\title{
DYNAMICS AND MONETARY POLICY IN A FAIR WAGE MODEL OF THE BUSINESS CYCLE
}

by David de la Croix, Gregory de Walque and Rafael Wouters

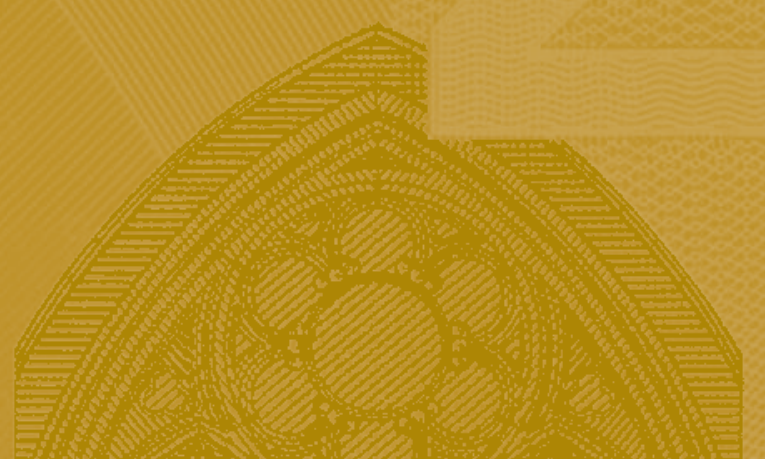




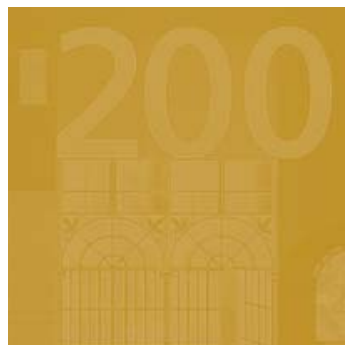

\section{WORKING PAPER SERIES} NO 780 / JULY 2007

\section{DYNAMICS AND MONETARY POLICY IN A FAIR WAGE MODEL OF THE BUSINESS}

by David de la Croix ${ }^{2}$, Gregory de Walque ${ }^{3}$ and Rafael Wouters ${ }^{4}$

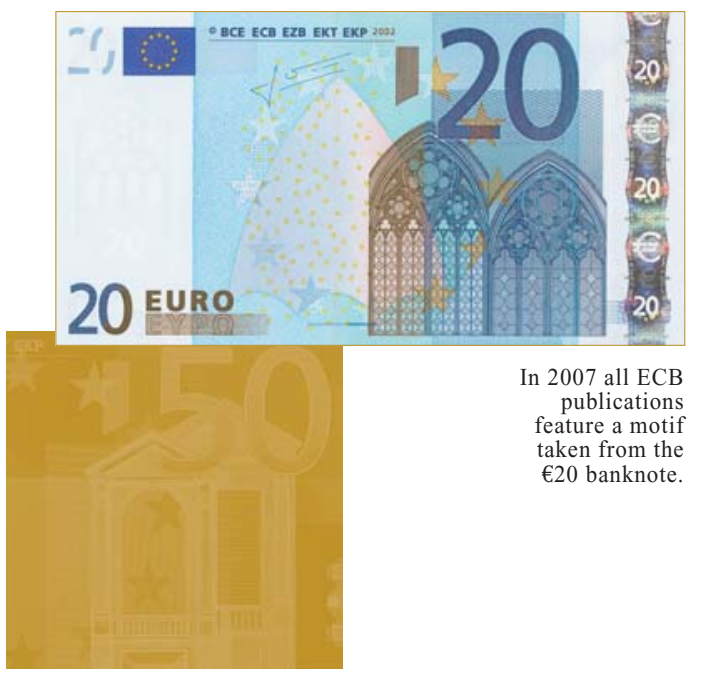

This paper can be downloaded without charge from http://www.ecb.int or from the Social Science Research Network electronic library at http://ssrn.com/abstract_id $=970900$.

I We thank the participants to the NBB project "Price and Wage Rigidities in an Open Economy" for their comments to previous drafts of the paper. We also acknowledge useful comments by J. Drèze and J. Lopez-Salido.

2 Department of Economics, Université catholique de Louvain, I, Place de l'Université, B-I 348 Louvain-la-Neuve, Belgium; e-mail: delacroix@core.ucl.ac.be 3 Department of Economics, University of Namur and National Bank of Belgium (NBB), Boulevard de Berlaimont 14, B-1000, Brussels, Belgium; e-mail: Gregory.DeWalque@nbb.be 


\section{ECB/CEPR Labour Market Workshop on "Wage and Labour Cost Dynamics"}

This paper was presented at the ECB/CEPR Labour Market Workshop on "Wage and Labour Cost Dynamics", held on 14-15 December 2006 in Frankfurt am Main, Germany. The workshop was organized by Torben M Andersen (Universitet Aarhus and CEPR), Samuel Bentolila (CEMFI and CEPR), Ana Lamo (ECB) and Jarkko Turunen (ECB). The conference programme, including papers, can be found on the ECB's web site http://www.ecb.int/events/conferences/html/wage_and_labour.en.html

The views expressed in the paper are the author's own and do not necessarily reflect those of the Eurosystem.

\footnotetext{
(C) European Central Bank, 2007

Address

Kaiserstrasse 29

60311 Frankfurt am Main, Germany

Postal address

Postfach 160319

60066 Frankfurt am Main, Germany

Telephone

+496913440

Internet

http://www.ecb.int

Fax

+496913446000

Telex

411144 ecb d

All rights reserved.

Any reproduction, publication and reprint in the form of a different publication, whether printed or produced electronically, in whole or in part, is permitted only with the explicit written authorisation of the ECB or the author(s).

The views expressed in this paper do not necessarily reflect those of the European Central Bank.

The statement of purpose for the ECB Working Paper Series is available from the ECB website, http://www.ecb.int. 


\section{CONTENTS}

Abstract

Non-technical summary

Introduction

1 Theoretical implications of the fair wage hypothesis

1.1 Households

1.2 Final output firms

1.3 Intermediate good firms

1.4 Aggregate conditions

1.5 Inflation stickiness

1.6 Long-run unemployment

1.7 Optimality

2 Fair wages in a New Keynesian DSGE

2.1 Households

2.2 Firms

2.2.1 Final output firms

2.2.2 Intermediate retail firms

2.2.3 Intermediate producers

2.3 Monetary policy

2.4 Estimation results

2.4.1 Estimated parameters and marginal likelihood of the model

2.4.2 Impulse response function

2.4.3 Alternative specifications of the effort function

3 Monetary policy implications

4 Concluding remarks

References

A Proof of proposition 3

B The loglinearized model

C Estimation results

Tables and figures

European Central Bank Working Paper Series 


\begin{abstract}
We first build a fair wage model in which effort varies over the business cycle. This mechanism decreases the need for other sources of sluggishness to explain the observed high inflation persistence. Second, we confront empirically our fair wage model with a New Keynesian model based on the standard assumption of monopolistic competition in the labor market. We show that, in terms of overall fit, the fair wage model outperforms the New Keynesian one. The extension of the fair wage model with lagged wage is judged insignificant by the data, but the extension based on a rent sharing argument including firm's productivity gains in the fair wage is not. Looking at the implications for monetary policy, we conclude that the additional trade-off problem created by the inefficient real wage behavior significantly affect nominal interest rates and inflation outcomes.
\end{abstract}

Keywords: Efficiency wage, effort, inflation persistence, monetary policy. JEL Classification numbers: E4, E5. 


\section{Non-technical summary}

In the conventional models of the labor market with monopolistic competition, workers set wages unilaterally and provide the labour input that is demanded by the firms. Such a modeling of the labor market faces two main shortcomings. The first one is that it fails to produce the macroeconomic stylized fact that wages are a-cyclical along the business cycle, while employment is highly pro-cyclical. This problem has been circumvented in the literature by adding nominal wage rigidities in the form of multi-period wage contracts. The second trouble raised by the monopolistic worker view is that it cannot generate structural unemployment as all adjustments take place along the intensive margin.

In reaction to this, labor economists have developed two competing theories. In the first one, called the frictional unemployment view, unemployed workers and labor force seeking firms do not meet at once. Firms have to post vacancies and finding a worker is a costly and time-consuming process. The second theory, which is at the centre of our attention in the present paper, is referred to as the efficiency or fair wage assumption. In this setting, workers choose their effort by comparing their current wage with the "outside option" which is function of the opportunity wage and the situation on the labor market. In reaction to this workers behavior, firms have an incentive to offer wages above the market clearing level in order to elicit effort. Even though this is an optimal behavior at the firm level, it generates involuntary unemployment at the aggregate level. The advantage of the fair wage assumption is that it allows to meet the empirically observed fact that firms are reluctant to reduce wages. The most often reported explanation is that firms anticipate that workers interpret wage cuts as a sign that their work is not valuated, affecting negatively their incentive to work efficiently.

In a static framework, the structural unemployment resulting of the fair wage assumption is viewed as a wage disciplining device. Therefore several authors attempted to introduce this mechanism into dynamic RBC models, in the hope that the real wage rigidities generated this way could help to solve the wage-employment puzzle. However, the general finding is that, in a dynamic framework, the fair wage assumption produces counter-cyclical effort and pro-cyclical wages. Indeed, in "booms", unemployment is low, reducing the workers' incentive to work and firms have to consent pay increases in order to maintain effort. Faced with this disappointing outcome, a line of research has consisted of introducing a reference to own past wages in the workers fair wage composition. The idea is that the negative effect on effort of a decline in unemployment can be counterbalanced by a wage increase. Furthermore, such intertemporal comparisons within the fair wage reference are supported by a large sociologic and microeconomic literature and they introduce the desired backward-looking features in the macroeconomic wage equation. 
In contrast with the previous literature, the present paper abandon the logarithmic representation of the fair wage norm which implied that firms find it optimal to keep effort constant over the business cycle. This way, we allow a positive relation between effort and wage in equilibrium with the effect that the returns to wages in terms of effort are less decreasing. In this sense, nonlogarithmic effort may prove to be a useful tool in solving the wage-employment puzzle. In the first part of the paper, we implement this effort specification into a simple RBC model with a closedform solution. We particularly focus on the elasticity of real wages to unemployment and further, on the consequences of this elasticity for inflation persistence. In the second part of the paper, we assess the ability of the model to match empirical data dynamics. For this exercise, we introduce the above described fair wage specification in a more complete New Keynesian model with price and wage time-dependent staggered wage contracts. This model is estimated on Euro area data using a Bayesian full information method and the outcome is compared with this obtained from the standard model with monopolistic workers setting unilaterally wages and labor supply. Our main findings are the following. First, the model with our fair wage specification outperforms the standard model in terms of overall empirical fit. Second, endogenous effort variations allow for reduced wage fluctuations, with the effect that the marginal cost reacts less to business cycle fluctuations. Third, the magnitude of the productivity shock is estimated lower in the model with endogenous effort, which meet recurrent observations in the literature. It is also noteworthy that time-dependent staggered wages combined with the reference to aggregate current wage in the effort function give the desired backward-looking features to the wage equation. Therefore, introducing a reference to own past wage in the fair wage norm does not bring any improvement. On the contrary, we find that giving the workers a share of the productivity gains meet their fairness requirement and elicit effort.

Finally, we conduct a welfare analysis to assess the role of monetary policy in the presence of real wage rigidities. Indeed, at the core of the fair wage assumption, we have that the effort judged fair by the workers is based on a comparison of their own wage with the aggregate wage and on the overall labour market situation. This leads to externality effects and implies inefficiently high unemployment level. Because of this, if the monetary policy focuses on inflation stabilization, output and employment dynamics will depart from the optimal response that can be computed when taking the externality effects into account. This highlights that, in the presence of real wage rigidities, monetary policy faces two conflicting objectives: inflation stabilization and employment stabilization. 


\section{Introduction}

Assuming that workers' effort are affected by the wage paid by the firm, efficiency wage theories have been judged to be very promising given the goal of understanding labor market characteristics. These theories have first been developed in static models, explaining the existence of unemployment as a result of the optimal response of firms to workers' behavior. For instance, in the gift exchange model of Akerlof (1982), the effort of an individual worker depends on a comparison between the current wage and a norm which includes the salaries perceived by other workers, the level of unemployment and unemployment benefits. The optimal response of the firm to this behavior is to offer a wage above the market-clearing level in return for which workers would provide a higher level of effort.

The view of labor relationships underlying the fair wage model is supported by a large number of studies both in applied economics and experimental psychology. For example Bewley (1998) interviewed business people, labor leaders and counselors of unemployment people in the US to understand why wages were almost never declining. The key result is that firms dislike pay cuts because they hurt morale. Good morale promotes high productivity, and other benefits such as less turnover, and a good company reputation that helps recruiting. Pay cuts hurt morale because of discomfort from reduced living standards and because of an insult effect - workers associate pay increases with approbation and reward.

While the efficiency wage literature was initially developed in a static framework Danthine and Donaldson (1990) introduce it in dynamic RBC model in order to assess whether the efficiency wage mechanism can help explain the wage-employment puzzle. Their finding is that the structural unemployment generated this way does not help to reduce the procyclicity of wages: as unemployment falls, effort tends to decrease and firms have to pay higher wages to maintain it. In the framework of the gift-exchange model, Collard and de la Croix (2000) show that this negative relationship between unemployment and wages can be attenuated by introducing a reference to past wages. ${ }^{1}$ In this set-up, effort does not only depend on the wage comparison with contemporaneous outside wage opportunities but also on the comparison with the workers' own lagged wage. This kind of argument is often used in the literature to motivate a role for a real wage rigidity in the wage equation. It reduces the countercyclical behavior of effort as the latter is not only raising with unemployment but also with wage increases. Danthine and Kurmann (2004) embed this idea into a New Keynesian general equilibrium model to analyze labor market and inflation dynamics. Their framework displays a series of interesting properties. Most importantly, the real rigidities implied by efficiency wages interact with nominal rigidities in such a way that the effect of monetary shocks on output is amplified and more persistent than in other monetary business cycle models. On the whole, this model indicates that the fair

\footnotetext{
${ }^{1}$ In the context of a shirking model, Alexopoulos (2004) breaks the procyclicality of wages by paying shirkers only a fraction of their wage instead of firing them. This way, the cost of being caught shirking is not reduced by the situation on the labor market in periods of high activity and effort is less countercyclical.
} 
wage approach constitutes a promising platform for a more complete New Keynesian synthesis.

In this paper, we pursue along this line by explicitly confronting the fair wage model with the standard New Keynesian model with sticky price and wages, in order to identify which features of the model are preferred by the data. We adopt an effort specification which is sufficiently general to allow effort to vary over the business cycle. This specification contrasts with the previous studies which selected a logarithmic effort function so that the Solow condition, characterizing the optimal firm behavior, implied a constant effort level. In the first part of the paper, we derive the theoretical properties of this effort specification in a simple RBC-type model for which we get closed form solution. In particular we assess how each parameter of the effort function affects the elasticity of real wages with respect to aggregate unemployment, and how this elasticity modifies the inflation persistence. Combining our result for the fair wage model with those of Bénassy (2004) for a model with a competitive labor market, we show that there exist parametrizations of the effort function for which the fair wage model generates more "endogenous price stickiness". This results contradicts the criticism formulated by Kiley (1997) against the efficiency wage assumption.

The ultimate test for our fair wage model is to confront it to the data. In a second step, we introduce our effort specification in a more complete DSGE model à la Christiano, Eichenbaum, and Evans (2005) or Smets and Wouters $(2003,2006)$. In addition, sticky nominal wage setting is introduced in order to compare the fair wage model with the standard New Keynesian model with sticky prices and wages. Variable effort affects the estimates of the total factor productivity process (see Burnside, Eichenbaum, and Rebelo (1993) for a discussion) but also the correct measure of the marginal cost that drives the price setting of the firms. Wage fluctuations are partially compensated by the endogenous effort fluctuations, so that the sensitivity of the marginal cost to output and employment variations is decreased. This mechanism can potentially decrease the need for nominal price stickiness to explain the observed low elasticity of inflation to output variations.

Two extensions of the fair wage model will be considered. The first one follows the argument of Collard and de la Croix (2000) and Danthine and Kurmann (2004), by considering lagged wages in the effort specification. The second extension is based on Danthine and Kurmann (2005) and argues for a rent sharing argument in the effort specification. Here, workers effort decision depends also on the fair treatment within the firm in the sense that workers expect to share in the productivity gains that are realized within the firm.

Finally we study the implications of the effort specification for monetary policy. The externality effect of aggregate wages and employment on the effort decision implies that the decentralized economy is characterized by an inefficient high level of unemployment. In addition, output and employment dynamics in the decentralized economy will deviate from the optimal response of the economy. Indeed a social planner would take into account these externality effects of the wage and employment decisions. Therefore, a monetary policy that concentrates on stabilizing the inflation pro- 
cess, will result in an output and employment response that deviate from the welfare optimal response. In that sense, monetary policy is faced with a trade-off problem between inflation stabilization on the one hand and output and employment gap stabilization on the other hand very much in the spirit of the Blanchard and Gali (2005) argument based on a real wage rigidity assumption. Our estimated model allows to evaluate the empirical relevance of this trade-off issue.

The paper is organized as follows. In Section 1 we derive the properties of the fair wage assumption in a simple general equilibrium model for which we get closed form solution. In Section 2, our modeling strategy is introduced in a more complete DSGE model, which allows us to evaluate the gain from our specification compared to the existing Smets and Wouters model. Section 3 draws lessons for monetary policy. Section 4 concludes.

\section{Theoretical Implications of the Fair Wage Hypothesis}

The objective of this section is to analyze how efficiency wage considerations modify real wage rigidity, unemployment, and the response of the economy to monetary shocks. In particular, we look at the interactions between real wage rigidities and inflation persistence. Accordingly, we model efficiency wages within an otherwise standard dynamic model with price staggering à la Calvo (1983). We follow closely the method developed by Bénassy (2004) who studies the effect of competitiveness on the good market and price stickiness. Closed form solutions can be obtained within a dynamic model under the following assumptions: logarithmic utility, no capital stock, multiplicative monetary shock. We can then study the link between the parameters of interest and a measure of inflation persistence. Notice that in this section, nominal stickiness only concerns prices; nominal wages can be freely reset every period. This assumption will be lifted in Section 2, where both prices and wages will be subject to Calvo's staggering.

\subsection{Households}

Effort at work has consequences in terms of utility. In fair wage models, utility is negatively related to the distance between the effort provided by household $j$, denoted $e_{t}(j)$, and the effort judged fair by the household $e_{t}^{\star}(j):\left[e_{t}(j)-e_{t}^{\star}(j)\right]^{2}$. In its simple form, the fair effort is a function of the real wage of the household $w_{t}(j)$, of labor market tightness and of the aggregate wage in the economy $w_{t}$ :

$$
e_{t}^{\star}(j)=\phi_{1} \frac{w_{t}(j)^{\psi}-\phi_{2}\left(\frac{1}{1-N_{t}}\right)^{\psi}-\phi_{3} w_{t}^{\psi}-\left(\phi_{0}-\phi_{2}-\phi_{3}\right)}{\psi}
$$

with the following parameter restrictions:

$$
\phi_{0} \in \mathbb{R}, \phi_{1}>0, \phi_{2}>0, \phi_{3} \in[0,1), \psi \in[0,1) .
$$




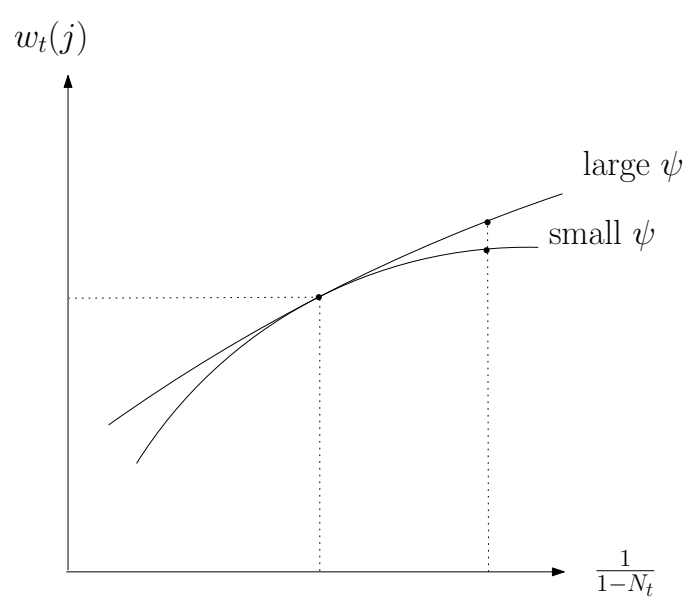

Figure 1: Iso-effort lines

$\phi_{0}$ and $\phi_{1}$ are scale parameters. $N_{t}$ is the aggregate employment rate, i.e. the average fraction of household's members having a job. The parameter $\phi_{2}$ measures the effect of the tightness of the labor market on individual effort. ${ }^{2}$ The parameter $\phi_{3}$ describes to which extent workers are sensitive to the alternative wage, i.e. the wage they could earn on average in the rest of the economy. Notice that $\phi_{2}$ and $\phi_{3}$ determine the influence of two aggregate variables on the firm; the relative importance of these two externalities will turn out to be important when we will discuss policy implications. Finally, the parameter $\psi$ describes the substitutability between the different elements in the effort function. To understand its role suppose that the firm faces a rise in the aggregate employment level. At given wage, effort will tend to diminish since external conditions have improved. The increase in the local wage which is required to keep effort constant will be higher if $\psi$ is large. This is illustrated in Figure 1. On the contrary, if aggregate employment decreases, only a small reduction in wage will keep effort constant when $\psi$ is large.

This effort function is a generalization of the logarithmic function found in the existing literature:

Lemma 1 For $\psi \rightarrow 0$ and $\phi_{0}=1$, effort is given by:

$$
e_{t}^{\star}(j)=\phi_{1}\left(\ln w_{t}(j)-\phi_{2} \ln N_{t}-\phi_{3} \ln w_{t}\right) .
$$

Proof: Compute the limit of $e_{t}^{\star}(j)$ when $\psi \rightarrow 0$ using l'Hospital rule.

Introducing effort into an otherwise standard money-in-the-utility function, the problem of the household is to maximize

$$
\sum \beta^{t}\left(\log c_{t}(j)+\sigma \log \left(m_{t}(j) / P_{t}\right)-n_{t}(j)\left[e_{t}(j)-e_{t}^{\star}(j)\right]^{2}\right)
$$

\footnotetext{
${ }^{2}$ We have preferred a formulation with $\left(1 /\left(1-N_{t}\right)\right)^{\psi}$ to one with $N_{t}^{\psi}$ to guarantee that the equilibrium $N_{t}$ is always below 1 .
} 
subject to the constraint:

$$
P_{t} c_{t}(j)+m_{t}(j)=P_{t} w_{t}(j) n_{t}(j)+\Pi_{t}+\mu_{t} m_{t-1}(j) .
$$

$n_{t}(j)$ is the fraction of family members working at date $t, \Pi_{t}$ denotes nominal distributed profits, and $\mu_{t}$ is a multiplicative shock affecting all existing money balances. The above formulation differs from the standard RBC model in one important point: labor does not enter in the utility function. This implies that the main mechanism at work will not be the standard intertemporal labor substitution effect usually driving RBC models. In this class of models the household supplies inelastically one unit of time, and only a fraction of time will be employed by the firm. We call $n_{t}(j)$ this fraction of time. One important point is that the utility drawn from the job itself is separable from the utility drawn from consumption so that effort is independent of wealth.

The first order necessary conditions for a maximum are:

$$
\begin{aligned}
e_{t}(j) & =\phi_{1} \frac{w_{t}(j)^{\psi}-\phi_{2}\left(\frac{1}{1-N_{t}}\right)^{\psi}-\phi_{3} w_{t}^{\psi}-\left(\phi_{0}-\phi_{2}-\phi_{3}\right)}{\psi} . \\
1 / c_{t}(j) & =\lambda_{t}(j) P_{t} \\
\sigma / m_{t}(j) & =\lambda_{t}(j)-\beta \mathrm{E}_{t}\left[\left(\lambda_{t+1}(j) \mu_{t+1}\right]\right.
\end{aligned}
$$

and the transversality condition

$$
\lim _{t \rightarrow \infty} \beta^{t} \frac{m_{t}(j)}{P_{t} c_{t}(j)}=0
$$

The first equation gives optimal effort as a function of real wages and employment rate. The second and third equations can be combined into

$$
\frac{m_{t}(j)}{P_{t} c_{t}(j)}=\sigma+\beta \mathrm{E}_{t}\left[\frac{m_{t+1}(j)}{P_{t+1} c_{t+1}(j)}\right]
$$

The only solution to this difference equation which satisfies the transversality condition is the constant solution:

$$
\frac{m_{t}(j)}{P_{t} c_{t}(j)}=\frac{\sigma}{1-\beta}
$$

\subsection{Final Output Firms}

Final output is produced with a combination of intermediate inputs $y_{i}$ by competitive firms. Their production function is:

$$
Y_{t}=\left[\int_{0}^{1}\left(y_{t}(i)\right)^{\theta} d i\right]^{1 / \theta}
$$


The elasticity of substitution between intermediate goods is $1 /(1-\theta)$ with $\theta \in(0,1)$. The parameter $\theta$ can be seen as an index of competitiveness. Each competitive firm maximizes profits:

$$
P_{t}=\left[\int_{0}^{1}\left(y_{t}(i)\right)^{\theta} d i\right]^{1 / \theta}-\int_{0}^{1} p_{t}(i) y_{t}(i) d i
$$

which leads to an isoelastic demand for intermediate good $i$ :

$$
y_{t}(i)=\left(\frac{p_{t}(i)}{P_{t}}\right)^{1 /(\theta-1)} Y_{t}
$$

The aggregate price $P_{t}$ is a CES index of the intermediate good prices:

$$
P_{t}=\left[\int_{0}^{1}\left(p_{t}(i)\right)^{\theta /(\theta-1)} d i\right]^{(\theta-1) / \theta} .
$$

\subsection{Intermediate Good Firms}

Given the demand $y_{t}(i)$, an intermediate firm hires labor input $n_{t}(i)$ and requests effort level $e_{t}(i)$ to produce the demanded quantity through the following technology:

$$
y_{t}(i)=A\left(e_{t}(i) n_{t}(i)\right)^{\alpha} \text {. }
$$

The parameter $A$ is an index of productivity. With marginal decreasing returns $(\alpha<1)$, the marginal productivity will differ across firms as soon as employment differ across them (as in Gali, Gertler, and Lopez-Salido (2001)). The intermediate firm minimizes costs $w_{t}(i) n_{t}(i)$ subject to technology (6) and effort (1). First order conditions are:

$$
\begin{aligned}
w_{t}(i) & =A v_{t}(i) \alpha y_{t}(i) / n_{t}(i) \\
n_{t}(i) & =A v_{t}(i) \alpha\left[y_{t}(i) / e_{t}(i)\right]\left[\phi_{1} w_{t}(i)^{\psi-1}\right]
\end{aligned}
$$

where $v_{t}(i)$ is the Lagrange multiplier associated to the production constraint. $1 / v_{t}(i)$ is also the markup over marginal cost. Combining the two conditions we obtain

$$
e_{t}(i)=\phi_{1} w_{t}(i)^{\psi}
$$

We deduce from this equation the following result.

Proposition 1 (Effort and wages) Optimal effort set by firms is given by equation (7). It is constant if $\psi=0$. Otherwise, there is a positive relation in equilibrium between effort and wages. 
The intuition behind the above Proposition goes as follows. Firms increase wages up to the point where any marginal gain in effort is offset by an increase in the wage bill. This is translated into the condition that the elasticity of effort to wages should be equal to 1 in equilibrium (which is called in the literature the Solow (1979) condition). In the case $\psi=0$, i.e. when the effort function is logarithmic, this elasticity condition is equivalent to imposing a constant effort $\left(e_{t}(i)=\phi_{1}\right)$. Any negative shock to effort, such as a rise in aggregate employment, will be met by a rise in the firms wage so as to keep effort constant. When $\psi>0$, i.e., when wages and employment are high substitute in the effort function, the elasticity condition is no longer equivalent to keeping effort constant. Any rise in aggregate employment will also be met by a rise in the firms wage; if the wage is raised up to the point where effort stays constant, the elasticity of effort to wages would stay above 1, giving an incentive to firms to raise wages above that point. This arises because the derivative of effort with respect to wages decreases less fast when $\psi>0$. In some sense, the returns to wage in terms of effort are less decreasing.

This highlights that assuming logarithmic utility imposes a very strong restriction on effort. Our generalization of the effort function allows for cases where effort varies positively with wages.

We can now compute the aggregate wage. Equation (7) implies that the optimal firm wage is (using equation (1)):

$$
w_{t}(i)=\left[\frac{\phi_{2}}{1-\psi}\left(\frac{1}{1-N_{t}}\right)^{\psi}+\frac{\phi_{3}}{1-\psi} w_{t}^{\psi}+\frac{\phi_{0}-\phi_{2}-\phi_{3}}{1-\psi}\right]^{1 / \psi}
$$

which is the same in all firms. Hence we have $w_{t}(i)=w_{t}$ and

$$
w_{t}=w_{t}(i)=\left[\frac{\phi_{2}}{1-\psi-\phi_{3}}\left(\frac{1}{1-N_{t}}\right)^{\psi}+\frac{\phi_{0}-\phi_{2}-\phi_{3}}{1-\psi-\phi_{3}}\right]^{1 / \psi} .
$$

For this aggregate wage to be well defined, we need to make one of the following assumptions:

Assumption $11-\psi-\phi_{3}>0$.

Assumption $21-\psi-\phi_{3}<0$ and $\phi_{0}-\phi_{3}<0$.

Under Assumption 1, the real wage is defined for any $N_{t} \in(\bar{N}, 1)$ with

$$
\begin{aligned}
\bar{N} & =1-\left(\frac{\phi_{2}}{-\left(\phi_{0}-\phi_{2}-\phi_{3}\right)}\right)^{1 / \psi} & & \text { if } \phi_{0}-\phi_{2}-\phi_{3}<0 \\
& =0 & & \text { otherwise. }
\end{aligned}
$$

The real wage is an increasing function of the employment rate. Under Assumption 2, it is defined for any $N_{t} \in(0, \bar{N}) \subset(0,1)$. In that case, the real wage is a decreasing 
function of the employment level. If neither Assumption 1, nor Assumption 2 holds, then the real wage is not defined. It is interesting at this stage to remark the role played by the parameter $\psi$. When $\psi=0$, i.e. the effort function is logarithmic, the restriction imposed by Assumption 1 is not very strong. Indeed, $\phi_{3}$ is always below one, reflecting that the wage externality alone cannot overwhelm the direct effect of the firm's wage on effort. When $\psi$ is positive, the story is different. The joint forces of the externality $\left(\phi_{3}\right)$ and the high substitution in the effort function $(\psi)$ may in fact reverse the positive relationship between wages and employment.

We can now define a concept of real rigidity as being the inverse of the sensitivity of wages to employment. Loglinearizing the wage equation (8) around a steady state $(w, N)$, we find:

$$
\hat{w}_{t}=\frac{\phi_{2}}{1-\psi-\phi_{3}}\left(\frac{N(1-N)^{-1-\psi}}{w^{\psi}}\right) \hat{N}_{t}=\underbrace{\frac{\phi_{2} N(1-N)^{-1-\psi}}{\left(\phi_{0}-\phi_{2}-\phi_{3}\right)+\phi_{2}\left(\frac{1}{1-N}\right)^{\psi}}}_{\equiv \Omega} \hat{N}_{t}
$$

Where hatted variables denote deviations from steady state. Then $\Omega$ is the sensitivity to employment and $1 / \Omega$ is real wage rigidity.

Proposition 2 (Real Wage Rigidity) Under Assumption 1, at given employment rate, real wage rigidity $(1 / \Omega)$ decreases with the relative sensitivity of effort to employment $\phi_{2}$.

It decreases with the relative importance of the externality $\phi_{3}$.

Real rigidity decreases with $\phi_{2}$ : if $\phi_{2}$ is small, unemployment affects effort very slightly, and wages do not need to be changed much to respond to changes in market tightness. Real rigidity decreases with $\phi_{3}$ : if the externality is large, spill-over effects between firms are important, which act as a multiplier on the aggregate wage of small changes in employment.

Under Assumption 2, equation (8) describes a negative relation between aggregate real wages and the employment rate. This negative relation holds because firms can adjust wages each period, implying that the full effect of the externality $\left(\phi_{3}\right)$ is obtained almost instantaneously. The assumption that firms can change the wage at any moment will be lifted in Section 2. We will there assume that only a fraction of firms choose the nominal wage at a given point in time. This nominal sluggishness will delay the effect of the externality, keeping a short run positive effect of employment on the real wage, although the long-run effect remains negative.

We now derive the optimal price setting by the intermediate firm. At each time a fraction $1-\xi_{p}$ of firms sets a new price $p_{t}^{\star}(i)$. This price will still prevail in period $s$ with probability $\xi_{p}^{s-t}$. Nominal profits at time $s$ are:

$$
\Pi_{s}(i)=p_{t}^{\star}(i) y_{s}(i)-w_{s} P_{s} n_{s}(i)=p_{t}^{\star}(i) y_{s}(i)-w_{s} P_{s}\left[y_{s}(i)\right]^{1 / \alpha}\left[1 / e_{s}(i)\right]
$$


with $n_{s}(i)=\left[y_{s}(i)\right]^{1 / \alpha}\left[1 / e_{s}(i)\right]$. The firm maximized the discounted flow of expected real profits, multiplied by the marginal utility of consumption $1 / C_{s}$. We use the equilibrium conditions on the final good market $Y_{s}=C_{s}$ to write the objective of the firm:

$$
\mathrm{E}_{t} \sum_{s=t}^{\infty} \frac{\prod_{s}(i)}{P_{S} Y_{s}}=\mathrm{E}_{t} \sum_{s=t}^{\infty}\left(\beta \xi_{p}\right)^{s-t}\left(\frac{p_{t}^{\star}(i) y_{s}(i)}{P_{s} Y_{s}}-\frac{w_{s}}{Y_{s}}\left[y_{s}(i)\right]^{1 / \alpha}\left[1 / e_{s}(i)\right]\right)
$$

Using equations (4) and (7), the objective becomes:

$$
\mathrm{E}_{t} \sum_{s=t}^{\infty}\left(\beta \xi_{p}\right)^{s-t}\left[\left(\frac{p_{t}^{\star}(i)}{P_{S}}\right)^{\theta /(\theta-1)}-\frac{w_{s}^{1-\psi}}{\phi_{1} Y_{s}} Y_{s}^{1 / \alpha}\left(\frac{p_{t}^{\star}(i)}{P_{S}}\right)^{1 /(\alpha(\theta-1))}\right]
$$

The first-order condition for a maximum in $p_{t}^{\star}(i)$ is:

$$
\begin{aligned}
\left(p_{t}^{\star}(i)\right)^{(1-\alpha \theta) /(\alpha(1-\theta))} \mathrm{E}_{t} \sum_{s=t}^{\infty}\left(\beta \xi_{p}\right)^{s-t} P_{s}^{\theta /(1-\theta)} & \\
& =\frac{1}{\alpha \theta \phi_{1}} \mathrm{E}_{t} \sum_{s=t}^{\infty}\left(\beta \xi_{p}\right)^{s-t} \frac{w_{s}^{1-\psi}}{Y_{s}} Y_{s}^{1 / \alpha} P_{s}^{1 /(\alpha(1-\theta))}
\end{aligned}
$$

The optimal price $p_{t}^{\star}(i)$ determined by this equation does not depend on $i$. All firms which set an optimal price at time $t$ choose the same price $p_{t}^{\star}(i)=p_{t}^{\star}$.

\subsection{Aggregate Conditions}

Given that a fraction $1-\xi_{p}$ of firms set a new price each year, the average price level given in (5) follows:

$$
P_{t}^{\theta /(\theta-1)}=\left(1-\xi_{p}\right)\left(p_{t}^{\star}\right)^{\theta /(\theta-1)}+\xi_{p} P_{t-1}^{\theta /(\theta-1)}
$$

Following Yun (1996), aggregate output can be written as a function of aggregate inputs by :

$$
Y_{t}=\left(\frac{X_{t}}{P_{t}}\right)^{1 /(1-\theta)} A\left(\phi_{1} w^{\psi} N_{t}\right)^{\alpha}
$$

with :

$$
N_{t}=\int_{0}^{1} n_{t}(i) d i
$$

and

$$
X_{t}^{1 /(\theta-1)}=\left(1-\xi_{p}\right)\left(p_{t}^{\star}\right)^{1 /(\theta-1)}+\xi_{p} X_{t-1}^{1 /(\theta-1)}
$$

The equilibrium on the goods market implies

$$
Y_{t}=C_{t}
$$




\subsection{Inflation Stickiness}

Suppose there is a steady state which is saddle-point stable. To study inflation stickiness, we log-linearize the model (see Appendix A) and study how monetary shocks persist in the price system.

Proposition 3 After loglinearization around the steady state, the solution to equation (11) is of the form:

$$
\hat{P}_{t}=\rho \hat{P}_{t-1}+\sum_{j=0}^{\infty} b_{j} E_{t} \hat{M}_{t+j}
$$

Inflation stickiness $\rho$ increases with the Calvo probability $\xi_{p}$ and increases with the degree of real wage rigidity $1 / \Omega$. At given rigidity $1 / \Omega$, it also increases with $\psi$, the degree of substitution between wage and employment in the effort function.

Proof: see Appendix A.

The parameter $\rho$ is a good measure of inflation stickiness because we can write (16) as:

$$
\hat{P}_{t}-\hat{P}_{t-1}=\rho\left(\hat{P}_{t-1}-\hat{P}_{t-2}\right)+(1-\rho)\left(\hat{M}_{t}-\hat{M}_{t-1}\right)
$$

Proposition 3 says that when wages and employment are highly substitute in the effort function, effort co-moves with wages (equation (7)), the influence of the wage on the marginal cost is compensated by changes in effort and inflation is more persistent.

We may compare the expression computed for $\rho$ to the expression computed by Bénassy (2004) for this parameter under the assumption of a Walrasian labor market. From this exercise we conclude that the fair wage model generates more endogenous price stickiness than the traditional competitive labor market model if

$$
\frac{(1-\psi) \Omega}{\psi \Omega+1}<\sigma_{l}+\alpha
$$

where $\sigma_{l}$ is the inverse of elasticity of the work effort with respect to the real wage. This condition is easily verified for $\psi$ and $\phi_{3}$ relatively large. This proves that the result obtained by Kiley (1997) that the efficiency wage assumption can never produce more endogenous price rigidity than the competitive labor market assumption can be circumvented by considering a somewhat more general effort function, with high substitution between wages and unemployment $(\psi)$ and/or large enough wage externalities $\left(\phi_{3}\right)$.

\subsection{Long-run Unemployment}

At steady state, all prices are equal, and output is given by (from (13)):

$$
Y=A\left(\phi_{1} w^{\psi} N\right)^{\alpha}
$$


Equation (8) can be rewritten:

$$
w^{\psi}=\frac{\phi_{0}-\phi_{2}-\phi_{3}}{1-\psi-\phi_{3}}+\frac{\phi_{2}}{1-\psi-\phi_{3}}\left(\frac{1}{1-N}\right)^{\psi}
$$

All firms are now alike so that

$$
w=v \alpha Y / N
$$

The optimal price setting rule (11) leads to:

$$
v=\theta \text {. }
$$

Using these four equations, the steady state employment rate $N$ satisfies:

$$
(A \theta \alpha)^{\frac{1}{1-\alpha \psi}} \phi_{1}^{\frac{\alpha}{1-\alpha \psi}} N^{\frac{-(1-\alpha)}{1-\alpha \psi}}=\left[\frac{\phi_{0}-\phi_{2}-\phi_{3}}{1-\psi-\phi_{3}}+\frac{\phi_{2}\left(\frac{1}{1-N}\right)^{\psi}}{1-\psi-\phi_{3}}\right]^{\frac{1}{\psi}}
$$

Under Assumption 1, the left hand side decreases monotonically from $+\infty$ to

$$
\ell=(A \theta \alpha)^{\frac{1}{1-\alpha \psi}} \phi_{1}^{\frac{\alpha}{1-\alpha \psi}}
$$

as $N$ goes from 0 to one. The right hand side increases monotonically from

$$
\imath=\left[\frac{\phi_{0}-\phi_{3}}{1-\psi-\phi_{3}}\right]^{\frac{1}{\psi}}
$$

to $+\infty$ as $N$ goes from 0 to one. From these properties we can deduce that there is always a unique solution to equation (17).

Proposition 4 Under Assumption 1, there is a unique steady state employment rate $N$ which satisfies equation (17). $N$ is a positive function of competitiveness $\theta$ and productivity $A$. It is a negative function of effort sensitivity to employment $\phi_{2}$. If $\phi_{0} \geq 1-\psi$, it is a negative function of the strength of the wage externality $\phi_{3}$.

Under Assumption 1, equation (17) can be interpreted within the usual textbook WSPS framework (left panel of Figure 2). The left hand side represents the PS curve (pricedetermined real wage) and is a decreasing function of $N$. The right hand side represents the WS curve (wage-setting curve), it is increasing in $N$ and represents the real wage underlying the efficiency wage set-up. The PS curve depends on productivity $A$, on competitiveness on the product market $\theta$, and on $\phi_{1}$ which directly influences labor productivity through the level of effort.

A rise in competitiveness reduces the markup of firms, shifts the PS curve to the right, increases the level of employment and reduces unemployment. A rise in effort sensitivity to employment shifts the WS curve to the left, which lowers employment. When externalities are strong $\left(\phi_{3}\right)$, the WS curve is higher and unemployment is higher too. 

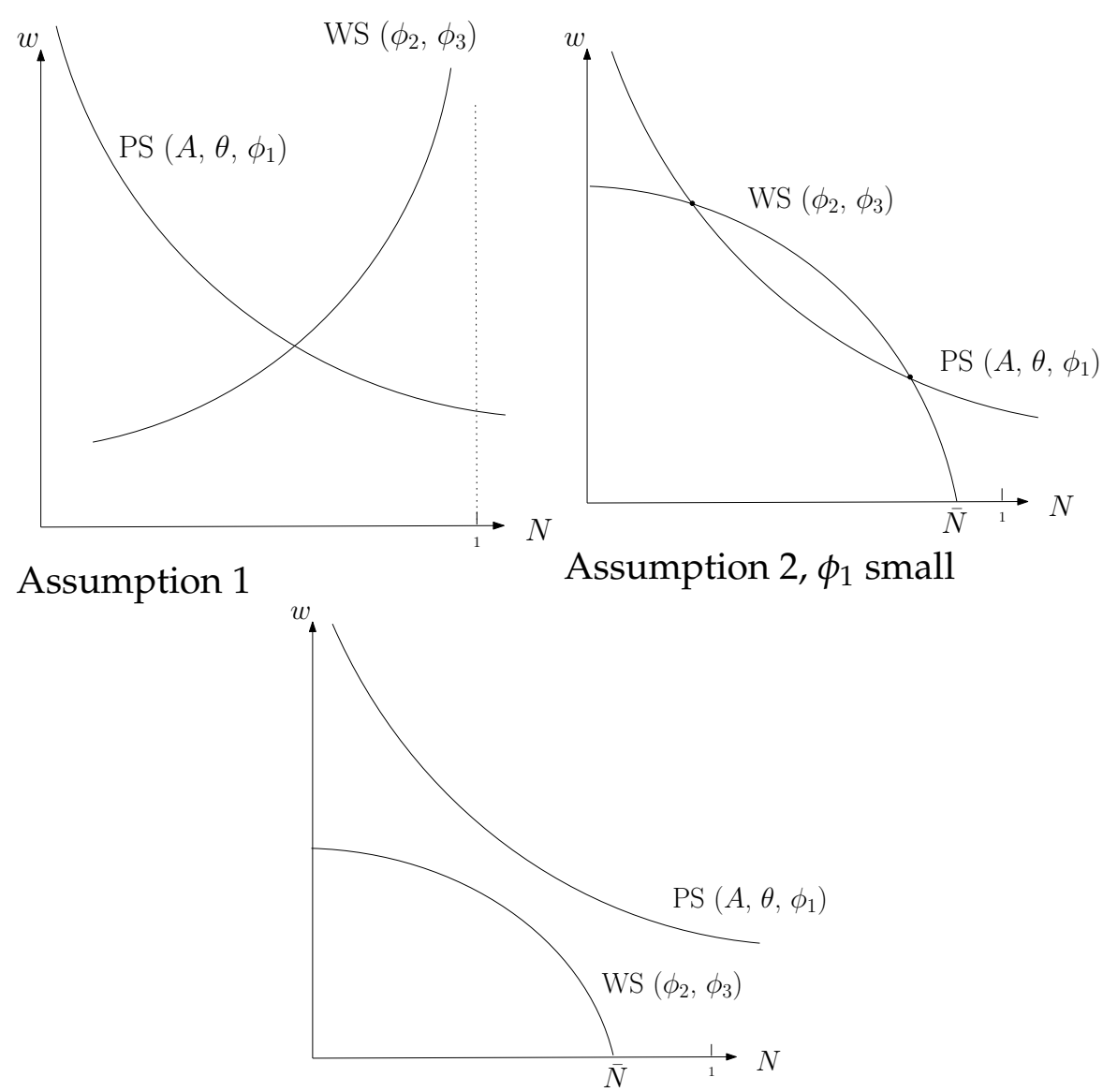

Assumption 2, $\phi_{1}$ large

Figure 2: Equilibrium Unemployment Rate

Under Assumption 2, the left hand side decreases monotonically from $+\infty$ to $\ell$ as $N$ goes from 0 to one. The right hand side decreases monotonically from $\imath$ to 0 as $N$ goes from 0 to $\bar{N}$, where $\bar{N}$ has been defined in equation (9). From these properties we can deduce that different cases are possible. Figure 2 represents two of them. In the top right panel, there are two long-run employment equilibria. In the bottom panel, there is none. One can move from the situation of the top panel to the one in the bottom panel by raising the parameter $\phi_{1}$ (for example). Starting with a low value of $\phi_{1}$ and two equilibria, raising $\phi_{1}$ will progressively shifts the PS curve upward. There will be one value of $\phi_{1}$ for which the two curves will be tangent to each other; this point is called a tangent bifurcation (see de la Croix and Michel (2002)). The two equilibria collide and disappear. For $\phi_{1}$ above this critical value, long-run equilibria do not exist any more. A sharp characterization of this phenomenon using the tools of bifurcation theory is beyond the scope of this paper. In the applied model of Section 2 we can always choose $\phi_{1}$ to guarantee the existence of a long-run equilibrium. From the estimation procedure it appears that the larger steady state is saddle-point stable. Notice that some comparative static results of Proposition 4 are reversed for the high steady state: 
Proposition 5 Under Assumption 2, assume that $\phi_{1}$ is low enough to guarantee the existence of at least one steady state employment rate $N$.

(a) The largest equilibrium employment rate $N$ is a negative function of competitiveness $\theta$ and productivity $A$.

(b) It is a negative function of effort sensitivity to employment $\phi_{2}$. If $\phi_{0} \geq 1-\psi$, steady state employment is always a positive function of the strength of the wage externality $\phi_{3}$.

Result (a) will turn out to be important to understand the effect of a productivity shock on employment in Section $2 .{ }^{3}$ Result (b) comes from the fact that a rise in effort sensitivity to employment shifts the WS curve downward, which decreases employment. When externalities are strong $\left(\phi_{3}\right)$, the WS curve moves upward and employment is higher too.

\subsection{Optimality}

Following the discussion in Shapiro and Stiglitz (1984), it is clear that the two externalities which are present in the effort function have opposite effects on the long-run employment outcome. The employment externality implies that firms do not take into account the negative spillover effects of their employment decision on the general effort level in the economy. Under Assumption 1, neglecting this social cost leads to overemployment. On the other hand, the wage externality implies that firms do not take into account the negative spillover effect of their wage decision on the overall effort level. By increasing the opportunity wage for workers, the decentralized wage policy results in higher wages than is socially optimal. The net outcome of the two externalities will depend on the relative size of the parameters $\phi_{2}$ and $\phi_{3}$, but in general the outcome under the decentralized economy will not equal the social optimal employment rate.

\section{Fair Wages in a New Keynesian DSGE}

In this section we introduce the fair wage model into the standard New Keynesian model with sticky prices and wages of Smets and Wouters (2003). This model is significantly richer than the stylized framework developed in the previous version: it has physical capital, nominal wage stickiness à la Calvo, and a monetary policy rule à la Taylor. It also includes some additional propagation mechanisms such as external habit formation, adjustment costs on investment in physical capital and costly variable degree of capital utilization.

\footnotetext{
${ }^{3}$ Although we shall compute the impulse response function of employment to a temporary productivity shock, this shock is persistent enough to deliver results close to those of a permanent change in productivity, as the one highlighted in Proposition 5.
} 


\subsection{Households}

Compared to the previous section, we generalize the instantaneous utility function of each household $j$ by including an external habit variable $\left(H_{t}\right)$ and by allowing the intertemporal elasticity of consumption to be different from one. Therefore the instantaneous utility takes the form

$$
U_{t}(j)=\left(\frac{\left(C_{t}(j)-H_{t}\right)^{1-\sigma_{c}}}{1-\sigma_{c}}-n_{t}(j)\left[e_{t}(j)-e_{t}^{\star j}\right]^{2}\right)
$$

where $\sigma_{c}$ determines the intertemporal elasticity of substitution. The external habit variable is assumed to be proportional to aggregate past consumption: $H_{t}=h C_{t-1}$. The effort function is given by:

$$
\begin{aligned}
e_{t}^{j \star} & =\phi_{1} \frac{\left(w_{t}(j)\right)^{\psi}-\phi_{2}\left(\frac{1}{1-N_{t}}\right)^{\psi}-\phi_{3} w_{t}^{\psi}-\left(\phi_{0}-\phi_{2}-\phi_{3}\right)}{\psi}+\varepsilon_{t}^{e f} \\
\varepsilon_{t}^{e f} & =\rho_{e f} \varepsilon_{t-1}^{e f}-\zeta_{e f} \eta_{t-1}^{e f}+\eta_{t}^{e f} \text { and } \eta_{t}^{e f} \text { an i.i.d.-Normal error term }
\end{aligned}
$$

We introduced a stochastic component $\varepsilon_{t}^{e f}$ reflecting stochastic shifts in the effort supply preferences. The shock $\varepsilon_{t}^{e f}$ is assumed to be an $\operatorname{ARMA}(1,1)$ process with an i.i.d.normal error term. Households seek to maximize

$$
\mathrm{E}_{0} \sum_{t=0}^{\infty} \beta^{t} \cdot U_{t}(j)
$$

Household's total income consists of three components: labor income plus the net cash inflows from participating in state-contingent securities $\Lambda_{t}(j)$, the return on the capital stock diminished of the cost $\Psi\left(u_{t}(j)\right)$ associated with variations in the degree of capital utilization $u_{t}(j)$ and the dividends derived from the imperfect competitive intermediate firms described in the intermediate retail firms subsection below:

$$
\mathcal{Y}_{t}(j)=\left(w_{t}(j) n_{t}(j)+\Lambda_{t}(j)\right)+\left(r_{t}^{k} u_{t}(j) K_{t-1}(j)-\Psi\left(u_{t}(j)\right) K_{t-1}(j)\right)+\operatorname{Div}_{t}(j)
$$

State-contingent securities insure households against variations in household specific labor income so that the first term in the total income is equal to aggregate labor income and the marginal utility of wealth is identical across households.

Households maximize their objective function subject to an intertemporal budget constraint which is given by

$$
\frac{1}{R_{t}^{e}} \frac{B_{t}(j)}{P_{t}}=\frac{B_{t-1}(j)}{P_{t}}+\mathcal{Y}_{t}(j)-c_{t}(j)-i_{t}(j)
$$


with

$$
\begin{aligned}
R_{t}^{e} & =\frac{R_{t}}{\varepsilon_{t}^{b}} \text { and } \\
\varepsilon_{t}^{b} & =\rho_{b} \varepsilon_{t-1}^{b}+\eta_{t}^{b} \text { and } \eta_{t}^{b} \text { an i.i.d.-Normal error term }
\end{aligned}
$$

Households hold their financial wealth in the form of domestic bonds $B_{t}$. Bonds are one period securities with a nominal rate of return $R_{t}^{e}$ which is affected by a risk premium on bond holdings represented by the $\operatorname{AR}(1)$ shock $\varepsilon_{t}^{b}$. Households decide on their optimal consumption, bonds holding and effort. They also choose the capital stock, investment and capital utilisation in order to maximise their intertemporal objective function subject to the intertemporal budget constraint and the capital accumulation equation given by

$$
\begin{aligned}
K_{t} & =K_{t-1}(1-\tau)+\varepsilon_{t}^{i}\left[1-S\left(I_{t} / I_{t-1}\right)\right] I_{t}, \text { with } \\
\varepsilon_{t}^{i} & =\rho_{i} \varepsilon_{t-1}^{i}-\zeta_{i} \eta_{t-1}^{i}+\eta_{t}^{i} \text { and } \eta_{t}^{i} \text { an i.i.d.-Normal error term }
\end{aligned}
$$

where $I_{t}$ is the gross investment, $\tau$ is the depreciation rate, $S(\cdot)$ is an adjustment cost function increasing with changes in investment and $\varepsilon_{t}^{i}$ represents an investment specific technology shock.

\subsection{Firms}

As in Smets and Wouters (2003), firms decide on the quantities of labor and capital services to rent and they set prices optimally. However, in the efficiency wage set up, they also decide on wages. In the sequel of the paper, we will leave the flexible wage assumption of the previous section and introduce nominal wage rigidities à la Calvo. In order to circumvent aggregation problems, we modify the structure of the production sector as follows.

Intermediate producers operate in a competitive market. They hire capital and labor, and manage effort through their wage policy. Wages are assumed sticky. These firms sell their output to intermediate retail firms who buy the homogeneous intermediate products and transform them one-to-one into a differentiated product. The retail firms operate on a monopolistically competitive market with sticky prices. They sell their output to the flexible price final good sector whose firms act on a competitive market. The final good is an homogeneous good serving for consumption and investment purposes.

The distinction between the firms producing the intermediate goods and the monopolistically competitive retail firms allows to separate the price and wage setting decisions. Furthermore, if intermediate producers act on a competitive market, it results in the very convenient feature that intermediate producers share the same homogeneous marginal cost. 


\subsubsection{Final Output Firms}

Final output firms are as described in subsection 1.2. Hence equations (3) to (5) hold. The only difference is that instead of considering $\theta$, a static index of competitiveness, we now consider

$$
\begin{aligned}
\theta_{t} & =\frac{1}{1+\varepsilon_{t}^{\theta}}, \text { with } \\
\varepsilon_{t}^{\theta} & =\rho_{p} \varepsilon_{t-1}^{\theta}-\zeta_{p} \eta_{t-1}^{p}+\eta_{t}^{p} \text { and } \eta_{t}^{p} \text { an i.i.d.-Normal error term }
\end{aligned}
$$

where the stochastic parameter $\varepsilon_{t}^{\theta}$ represents the time-varying markup in the goods market. Shocks to this parameter are interpreted as cost-push shocks to the inflation equation.

\subsubsection{Intermediate Retail Firms}

Intermediate retail firms indexed by $h \in[0,1]$ face a demand for their product represented by equation (4). Given this demand, they buy homogenous intermediate products at a price $Z_{t}$ and transform them one-to-one into a differentiated product, incurring a fixed cost $\Phi$. Current nominal profits of intermediate retail firms can therefore be written as:

$$
\Pi_{S}(h)=\left(p_{t}(h)-Z_{t}\right) \cdot y_{t}(h)-Z_{t} \Phi
$$

We now derive the optimal price setting by the intermediate firm. At each time $t$ a fraction $1-\xi_{p}$ of firms sets a new price $p_{t}^{\star}(h)$. This price will still prevail in period $s$ with probability $\xi_{p}^{s-t}$. Firms that do not reset their price, index it to a weighted average of past inflation $\pi_{t-1}(h)$ and trend inflation $\bar{\pi}$

$$
p_{t}(h)=p_{t-1}(h) \cdot \pi_{t-1}^{\gamma_{p}} \cdot \bar{\pi}^{1-\gamma_{p}}
$$

The price-setting firm maximizes the discounted flow of expected real profits, using a discounting rate $\beta \rho_{t}$ consistent with the pricing kernel for nominal returns used by the shareholders-households: $\rho_{t+s}=\frac{\lambda_{t+s}}{\lambda_{t} P_{t+s}}$. Its objective is therefore

$\mathrm{E}_{t} \sum_{s=0}^{\infty}\left(\beta \xi_{p}\right)^{s} \frac{\lambda_{t+s}}{\lambda_{t}}\left(\tilde{p}_{t}^{\star} \frac{P_{t} \Pi_{l=0}^{s-1} \pi_{t+l}^{\gamma_{p}} \cdot \bar{\pi}^{1-\gamma_{p}}}{P_{t+s}}\right)^{1 /\left(\theta_{t+s}-1\right)} Y_{t}\left(\widetilde{p}_{t}^{\star} \frac{P_{t} \Pi_{l=0}^{s-1} \pi_{t+l}^{\gamma_{p}} \cdot \bar{\pi}^{1-\gamma_{p}}}{P_{t+s}}-z_{t+s}\right)$

with $\widetilde{p}_{t}^{\star}=p_{t}^{\star} / P_{t}$ and $z_{t}=Z_{t} / P_{t}$. Note that the $h$ index has disappeared since all the firms that set an optimal price at the same period share the same expected sequence of real production costs.

Given the definition of the price index in (5), its law of motion is

$$
P_{t}^{\theta_{t} /\left(\theta_{t}-1\right)}=\left(1-\xi_{p}\right)\left(p_{t}^{\star}\right)^{\theta_{t} /\left(\theta_{t}-1\right)}+\xi_{p}\left(P_{t-1} \cdot \pi_{t-1}^{\gamma_{p}} \bar{\pi}^{1-\gamma_{p}}\right)^{\theta_{t} /\left(\theta_{t}-1\right)}
$$




\subsubsection{Intermediate Producers}

There is a continuum of competitive intermediate producers indexed by $i \in[0,1]$. Each firm hires labor input, capital input and request effort level $e_{t}(i)$ to produce $q_{t}(i)$ through the following technology:

$$
q_{t}(i)=\varepsilon_{t}^{a}\left(e_{t}(i) n_{t}(i)\right)^{\alpha} \kappa_{t}(i)^{1-\alpha}
$$

where $\varepsilon_{t}^{a}$ is the productivity shock assumed to follow an $\operatorname{AR}(1)$ process with an i.i.d.normal error term and $\kappa_{t}(i)$ is the effectively utilized capital stock given by $\kappa_{t}(i)=$ $u_{t} K_{t-1}(i)$. Real profits are

$$
z_{t} q_{t}(i)-w_{t}(i) n_{t}(i)-r_{t}^{k} \kappa_{t}(i)
$$

Profit maximization results in an optimal demand for capital and labor. As the intermediate good producers act on a competitive market, they all share the same real marginal cost

$$
z_{t}(i)=z_{t}=\frac{1}{\varepsilon_{t}^{a}} \cdot\left(\frac{w_{t}(i)}{e_{t}(i)}\right)^{\alpha}\left(r_{t}^{k}\right)^{1-\alpha} \alpha^{-\alpha}(1-\alpha)^{-(1-\alpha)}
$$

Therefore, the wage per efficient unit of labor is identical through firms $i$. The combination of the optimal demand for capital and (18) yields that all the intermediate producers share the same capital-efficient labor ratio. This implies that the first order conditions for capital and labor may be aggregated over the intermediate firms. ${ }^{4}$

Let us consider that firms can only reset their nominal wage with a Calvo probability $1-\xi_{w}$. Furthermore, the firms that do not optimize their wage index it to a weighted average of past inflation and trend inflation so that

$$
W_{t}(i)=W_{t-1}(i) \cdot \pi_{t-1}^{\gamma_{w}} \cdot \bar{\pi}_{t}^{1-\gamma_{w}}
$$

The objective function of an intermediate producer firm is

$$
\mathrm{E}_{t} \sum_{s=0}^{\infty}\left(\beta \xi_{w}\right)^{s} \frac{\lambda_{t+s}}{\lambda_{t}} \frac{1}{P_{t+s}}\left[Z_{t+s} q_{t+s}(i)-W_{t}^{\star}(i) n_{t+s}(i) \cdot \Pi_{l=0}^{s-1} \pi_{t+l}^{\gamma_{w}} \cdot \bar{\pi}_{t}^{1-\gamma_{w}}-P_{t} r_{t}^{k} \kappa_{t}(i)\right]
$$

with

$$
e_{t+s}(i)=\phi_{1} \frac{\left(\frac{W_{t}^{\star}(i)}{P_{t}} \Pi_{l=0}^{s-1} \pi_{t+l}^{\gamma_{w}} \cdot \bar{\pi}^{1-\gamma_{w}}\right)^{\psi}-\phi_{2}\left(\frac{1}{1-N_{t+s}}\right)^{\psi}-\phi_{3} w_{t+s}^{\psi}-\left(\phi_{0}-\phi_{2}-\phi_{3}\right)}{\psi}+\varepsilon_{t}^{e f}
$$

Firms decide on their wage in order to optimize the effort response of their workers over the expected contract length. Given that a fraction $1-\xi_{w}$ of firms sets a new wage each period and that the complementary proportion indexes it, the average wage level can be described as

$$
W_{t}=\xi_{w} \cdot W_{t-1} \cdot \pi_{t-1}^{\gamma_{w}} \cdot \bar{\pi}_{t}^{1-\gamma_{w}}+\left(1-\xi_{w}\right) \cdot W_{t}^{\star}
$$

\footnotetext{
${ }^{4}$ This point is important since it also implies that all the firms that re-set optimally their wage at a given period choose the same wage (cf. appendix B)
} 


\subsection{Monetary Policy}

In contrast with the first section, the monetary authorities are assumed to follow a generalized Taylor rule, responding gradually to deviations of inflation with respect to the steady-state inflation and to level and growth rate deviations of the output gap $\hat{Y}_{t}-\hat{Y}_{t}^{p}$. Written in percentage deviation from steady-state, the generalized Taylor rule is of the form

$$
\begin{aligned}
& \hat{R}_{t}=\rho \cdot\left(\hat{R}_{t-1}\right)+(1-\rho)\left[r_{\pi} \hat{\pi}_{t}+r_{y}\left(\hat{Y}_{t}-\hat{Y}_{t}^{p}\right)\right] \\
& +r_{\Delta y}\left[\left(\hat{Y}_{t}-\hat{Y}_{t}^{p}\right)-\left(\hat{Y}_{t-1}-\hat{Y}_{t-1}^{p}\right)\right]+\varepsilon_{t}^{r} \\
& \text { with } \varepsilon_{t}^{r}=\rho_{r} \varepsilon_{t-1}^{r}+\eta_{t}^{r} \text { and } \eta_{t}^{r} \text { an i.i.d.-Normal error term }
\end{aligned}
$$

The monetary policy rule is affected by a persistent interest rate shock $\varepsilon_{t}^{r}$, assumed to follow a first-order autoregressive process.

The output gap is defined as the difference between actual and potential output. The actual output is represented by the final good sector output (equation (3)). This final good serves for consumption and investment purposes, as well as for government spending and to pay the capacity utilization adjustment costs:

$$
\begin{aligned}
Y_{t} & =C_{t}+I_{t}+G_{t}+\Psi\left(u_{t}\right) K_{t-1} \\
\text { with } G_{t} & \equiv \varepsilon_{t}^{g}=\rho_{g} \varepsilon_{t-1}^{g}+\rho_{a g} \eta_{t}^{a}+\eta_{t}^{g} \text { and } \eta_{t}^{g} \text { an i.i.d.-Normal error term }
\end{aligned}
$$

The potential output is defined consistently with the DSGE model developed above. It is the output that would prevail in the economy with flexible prices and wages in absence of the inefficient cost-push shocks.

\subsection{Estimation Results}

The model presented above is first loglinearized around a steady state (see Appendix B). Next, the loglinearized equations are used to estimate the parameters with a Bayesian full information approach following the applications in Smets and Wouters (2003) and (2005). Data are for the Euro zone and the estimation period is 1974:1-2005:4. The seven macroeconomic time series used for estimation are the growth rate in real GDP, consumption, investment, real wages, the inflation rate in the GDP deflator, the short term interest rate and employment. These variables allow us to identify the seven structural shocks that appear in the model: the total factor productivity shock, the investment-specific technology shock, the public spending shock, the risk premium shock, the price markup shock, the monetary policy shock and a preference shock affecting the efficiency wage (replacing the wage markup shock in the standard New Keynesian model). A limited number of structural parameters, which are very poorly identified by our estimation strategy, are fixed at standard values (see Appendix C). Two parameters of the effort function $\left(\phi_{0}\right.$ and $\left.\phi_{1}\right)$ serve to scale the steady state so that the unemployment rate is 5 percent and the effort level is one. All the other parameters are estimated, together with the constant trend growth rate and inflation rate. 
The prior distribution around the parameters are the ones used in Smets and Wouters (2006). In order to compare the fair wage model with the standard New Keynesian model with labor in the utility function and a wage markup shock, we also reestimate this standard model on the same dataset and consider this as the reference point in further discussions.

\subsubsection{Estimated Parameters and Marginal Likelihood of the Model}

The estimation results are displayed in Table 1 . The estimates for most of the parameters in the fair wage model and the standard New Keynesian model are close and similar to the previous estimation outcomes reported in the literature. However, there are also some interesting differences. Looking first at the stochastic shock processes, it is not surprising that the estimated standard error of the total-factor productivity shock is lower in the fair-wage model. In line with the arguments in Burnside, Eichenbaum, and Rebelo (1993) and Basu (1996), the magnitude of this productivity shock is lower after accounting for the variable effort level in the production process. Additionally, the estimated fixed costs in the production function is lower in the fair wage model and this reduces further the role of the total factor productivity shock in the model. The estimated processes for the markup price shock and the wage shock also change: the standard errors increase but the shocks become less persistent in the fair wage setup. As a consequence, the contribution of these shocks to the inflation dynamics, especially over a longer horizon, will decrease. This result indicates that the persistence of inflation is better captured in the fair wage model.

In terms of the behavioral parameters, there is a noticeable decline in the capital adjustment cost and the habit parameter in the fair-wage model: both consumption and investment will have a quicker but less persistent response to all types of shocks and especially to innovations in the interest rate. The lower intertemporal elasticity of substitution (inverse of $\sigma_{c}$ ) further reduces the impact of interest rate shocks. The estimated price and wage Calvo parameters are very similar in the two models. The implied average duration of the price contract remain very high (more than two years) despite the argument of Proposition 3 that the endogenous effort reaction would stabilize the marginal cost sufficiently to allow for a lower Calvo parameter. The posterior estimate for the wage stickiness is very similar to the prior distribution, illustrating the lack of information in the data for estimating this parameter. It is interesting to note that a lower prior on wage stickiness results in a lower posterior estimate as well without affecting strongly the posterior probability of the overall model. However, in that case the estimated parameters for the effort function are different and in line with a higher real wage rigidity that substitutes for the nominal stickiness. The estimated policy rule is also very similar in both models. The extreme case of completely flexible wages is strongly rejected by the data.

Let us finally consider the parameters describing the labor supply and effort decision. In the benchmark New Keynesian model, the elasticity of labor supply is relatively low $(1 / 2.92)$. In the fair wage model, the effort equation replaces the labor supply 
term in the utility function. The estimated elasticity of substitution between wages and employment in the effort function is $\psi=0.36$. Since $\psi$ is significantly above 0 , the general power function for effort that allows effort to vary over the business cycle is not rejected by the data. The effect of the labor market tightness on the effort level is small but significant (implied $\phi_{2}=0.004^{5}$ ), while the coefficient on the aggregate wage is relatively high $\left(\phi_{3}=0.795\right)$. The restricted version where the coefficient on the aggregate wage is fixed to one and equal to the effect of the worker's own wage on his effort decision is in fact slightly preferred by the data. This version of the model will be used in our discussion of the monetary policy implications in Section 3 because it simplifies drastically the solution of the social planner problem. Finally, remark that Assumption 2 holds: $1-\psi-\phi_{3}<0$. Aggregate wage externalities and substitutability in the effort function are so strong that the underlying long-run wage setting curve is negatively sloped. As explained after Proposition 2, this property is mitigated by the wage nominal sluggishness which will deliver a positively sloped wage curve.

The quality of the overall fit of the two models is measured by the marginal likelihood of the models. The fair wage model is able to outperform the New Keynesian model. This difference can be translated in a strong posterior odd ratio of 0.999 in favor of the fair wage model for an equal prior probability of the two models.

\subsubsection{Impulse Response Function}

To compare the dynamics in the two models we consider three impulse response functions more in detail. Figure 3 in Appendix D plots the impulse response function for a monetary policy shock in the fair wage model and in the benchmark New Keynesian model. First of all, it is clear from this graph that the real effect of the monetary policy shock on aggregate demand and employment is much less persistent in the fair wage model. This result reflects the change in the estimated parameters that govern the persistence in aggregate demand, and also the fact that the interest shock is less persistent in the fair wage model. The second and more important observation is that the responses of the real wage and the inflation rate to the monetary policy shock are very similar in the fair wage model and in the benchmark model. Combined, these two findings imply that the real wage reaction to changes in the labor market situation is much more persistent in the fair wage model compared to the model with monopolistic competition. This illustrates clearly how our fair wage model is able to generate a very high real wage rigidity, a mechanism that is absent in the standard New Keynesian model.

This persistence in the wage response results from the combination of wage staggering with the externality of the aggregate wage on effort. Following a restrictive monetary policy, the effort of workers will tend to increase as a reaction on the higher unemployment risk. Firms that get the opportunity to adjust their wage will tend to decrease the wage in order to manage the optimal employment/effort input-mix. In the consecutive periods, the decrease in the aggregate wage will erode the impact of the firm

\footnotetext{
${ }^{5}$ The coefficient $\phi_{2}^{\prime}$ reported in Table 1 to 3 is equal to the expression $\phi_{2}(1 /((1-N) w))^{\psi} N /(1-N)$.
} 
specific wage via the externality effect and effort will again raise above the firm's optimal level, leading to further wage declines. This process will stabilize only slowly over time as lower wages and marginal costs cause an increase in the markup of the sticky price final good sector and stimulate supply, while at the same time there is a substitution effect towards labor which also reduces the unemployment risk. As a result, real wages fall as long as employment is below its steady state level. The same profile in the employment-wage reaction is present in the other 'demand' type shocks like the risk-premium shock, the public spending shock and the investment-specific technology shock.

Figure 4 summarizes the impulse responses following a total-factor productivity shock. Aggregate demand increases only gradually following the shock, and therefore firms have to lower their demand for labor. The decline in employment stimulates the effort supply and given the efficient effort condition, the real wage will also increase. Compared to the benchmark New Keynesian model, output and real wages increase much less in the fair-wage model and most strikingly employment declines persistently. While in the standard model, the equalization of the marginal rate of substitution between leisure and goods to the real wage imply that employment will return to the steady state level, no such stabilizing mechanism is present in the fair wage model and fluctuations in the employment rate can be very persistent. Moreover in the fair wage model, the moderate increase in the real wage is partially compensated by higher effort levels so that the marginal cost and inflation is significantly lower compared to the benchmark New Keynesian model.

The impulse response functions to the effort shock are very similar to the responses to the wage shock in the standard New Keynesian model (Figure 5). Although the effort shock in the fair wage model reduces basically to an i.i.d. shock, while the wage markup shock has a higher persistence in the standard model, the impact on the real wage is very similar as a result of the higher persistence in wages in the fair wage version. Inflation is slightly less affected in the fair wage model due to the compensating effort reaction to wage fluctuations. The same divergence for the inflation response is observed for the price markup shock: the inflation reaction is also less persistent in the fair wage model.

\subsubsection{Alternative Specifications of the Effort Function}

In the literature on efficiency wages, different specifications for the effort function have been considered. Following the negative conclusions about the potential of the efficiency wage models to generate sufficient real wage rigidity, Collard and de la Croix (2000) and Danthine and Kurmann (2004) considered an optimal effort function that reacts on lagged wages instead of the contemporaneous wage. Once the lagged wage appears in the effort decision, the models with efficiency wages are able to generate the observed real wage rigidity. Alternatively, Danthine and Kurmann (2005) consider an effort function derived from the reciprocity motive of economic agents, that depends on the firm internal productivity level. The worker's effort decision will depend not 
only on external opportunity wage considerations, but also on internal rent-sharing arguments. This reciprocity relationship between firms and workers find support in a vast body of microeconomic empirical evidence (Blanchflower, Oswald, and Garrett (1990) and Abowd, Creecy, and Kramarz (2002)). Given our reduced form setup for the optimal effort function, we can easily extend our specification to incorporate these additional arguments in our estimated model (cf. appendix B.2). The estimation results for these two generalizations are summarized in Table 2.

We found no empirical support for the specification with lagged wages as additional reference variable in the effort function: the coefficient on the lagged wage term is not significantly different from zero and the marginal likelihood of the extended model deteriorates. Given the sticky nominal wage assumption in our model, there is no need for adding more dynamics in the effort function. In fact the sticky wage assumption already produces a gradual adjustment of the aggregate reference wage to the newly optimized wages and in so doing provides the necessary persistence in the wage dynamics as observed in the various impulse response functions discussed before. The results for the model with a firm-internal rent-sharing argument performs slightly better than the baseline fair wage specification and the coefficient on this term is marginally significant and substitutes for the impact of the aggregate wage on effort.

\section{Monetary Policy Implications}

In this model, optimal monetary policy defined from the household welfare perspective should consider not only the costs of price and wage inflation and the cost of fluctuations in the natural output gap, but it should also take into account the inefficiencies in the wage and employment decisions that result from the externalities present in the workers effort decisions. These externalities create a wedge between the natural output, that is the outcome in the decentralized model assuming flexible price and wages, and the first best efficient output that would be attainable for the social planner. As argued in section 1.7, the difference between the natural and the efficient output and employment outcomes depend on the relative size of the two externalities. These differences can now be evaluated for the estimated models. In order to simplify the discussion, we concentrate on the model with $\phi_{3}$ restricted to one, that is the effort equation with an impact of aggregate wages equal to the impact of the worker specific wage, so that the wage plays only a distributive role in the social planner solution.

In terms of steady state levels, it turns out that for the estimated parameters the first best efficient output and employment rate is higher than in the natural economy: the efficient employment rate turns out to be 0.98 against the natural rate of 0.95 . The decentralized wage decision results in a too high wage by neglecting the externality effect on aggregate wages and this channel dominates the impact of the aggregate employment externality on effort and the wage decision. From the monetary policy point of view, this inefficiency in the decentralized steady state level is imposed and monetary policy is unable to affect these permanent steady state levels. However, more 
relevant for monetary policy is the wedge between the dynamic response in the first best efficient problem and the response under the decentralized setting. ${ }^{6}$ Here, monetary policy can contribute to welfare maximization by stabilizing the gap between the dynamic responses. Stabilization of this efficient output gap appears as an additional target for monetary policy and the important question then is to evaluate the empirical relevance of this trade-off.

In our evaluation of the trade-off problem, we concentrate on the dynamic responses of the productivity shock. By far this shock creates the most important divergence between the efficient and the natural output and employment fluctuations. The first best allocation imply that employment and effort remain constant at their efficient steady state level following any shock to the economy. The result is a strong increase in the efficient output following the productivity shock (see Figure 6). On the other hand, the natural output reaction in the decentralized setup is characterized by a persistent negative decline in employment and a more moderate increase in output. From this it is immediately clear that it makes a crucial difference for monetary policy which of the two output concepts is taken into account in its policy decision. In order to illustrate the importance also for the inflation outcomes, we compare in Figure 6 the impact of a productivity shock under the estimated policy rule, based on the natural output gap, and compare this with the same rule where the natural gap is replaced with the efficient gap. If monetary policy takes into account the higher efficient output response to the productivity shock, it will lower the real interest rate much more aggressively and this will result in a positive inflation response instead of the estimated negative impulse-response on inflation. Similar differences appear if we consider optimal monetary policy rules, instead of estimated instrument rules, with different output gap concepts in the objective function. These findings are in line with the results in Blanchard and Gali (2006). They consider the impact of real wage rigidity resulting from the bargaining process in a search and matching model of the labor market. They also conclude that the additional trade-off problem for monetary policy created by the inefficient real wage behavior is potentially important for the inflation outcome.

\section{Concluding Remarks}

In this paper, we considered efficiency wages along the gift-exchange argument in an otherwise standard DSGE model, by allowing effort of the workers to depend on workers' own wage, the average alternative wage and the employment rate in the economy (Akerlof (1982), Danthine and Donaldson (1990)). In addition sticky nominal wage setting is introduced in order to compare the fair wage model with the standard New Keynesian model with sticky price and wages. Contrary to the previous studies which selected an effort function implying constant effort over the business cycle, our effort specification is sufficiently general to allow effort to vary over the business cycle. We

\footnotetext{
${ }^{6}$ See Gali, Gertler, and Lopez-Salido (2005) for a discussion of the welfare costs of cyclical fluctuations in the output gap, and Blanchard and Gali (2005) for a discussion of the monetary policy implications.
} 
showed that, when effort is variable, wage fluctuations are partially compensated by the endogenous effort fluctuations, so that the sensitivity of the marginal cost to output and employment variations is decreased. This mechanism decreases the need for nominal price stickiness to explain the observed low elasticity of inflation to output variations. However, the fitted nominal price stickiness in the baseline fair-wage model remains very high, basically because of the productivity shocks that have a direct impact on the marginal cost. Therefore, these shocks would lead to large price effects in a model with more flexible prices. Note however, that this result is in line with evidence from SVAR exercises claiming that prices react more strongly to productivity shocks than to demand shocks (Christiano, Eichenbaum, and Vigfusson 2003).

In terms of overall empirical fit, the fair wage model outperforms the standard New Keynesian model as estimated in Smets and Wouters (2003) in which the real wage is determined by the marginal rate of substitution between leisure and consumption. Two extensions of the fair wage model have been considered. The first one follows the argument of Collard and de la Croix (2000) and Danthine and Kurmann (2004), by considering lagged wages in the effort specification. In this set-up, effort does not only depend on wage comparisons with contemporaneous outside wage opportunities but also on comparisons with the workers' own lagged wage. Estimates of this extended effort specification in our model does not indicate an important role for this additional real wage rigidity argument. The second extension is based on Danthine and Kurmann (2005) and argues for a rent sharing argument in the effort specification. Here, workers effort decision depends also on the fair treatment within the firm in the sense that workers expect to share in the productivity gains that are realized within the firm. Our estimation results confirm that there is some role for internal rent sharing.

The importance of the labor market structure for welfare analysis and monetary policy conclusions was already stressed recently by Levin et al. (2005) within the context of a New Keynesian model. Our results illustrate again the importance of the labor market assumptions for policy conclusions. In particular, our conclusions resemble the findings of Blanchard and Gali (2005) in showing the challenging consequences of real wage rigidities for monetary policy.

Efficiency wage considerations are potentially an important mechanism to understand wage rigidity and persistent employment shocks. The effort function in our specification of the household problem should be derived from the optimizing behavior of utility maximizing agents along the lines of Danthine and Kurmann (2005). More research is needed to evaluate the consistency between micro and macro estimates of these efficiency wage considerations.

\section{References}

Abowd, John, Robert Creecy, and Francis Kramarz. 2002. "Computing Person and Firm Effects Using Linked Longitudinal Employer-Employee Data." Technical Report, Cornell University. 
Akerlof, George. 1982. "Labor contracts as partial gift exchange." Quarterly Journal of Economics 97:543-569.

Alexopoulos, Michelle. 2004. "Unemployment and the business cycle." Journal of Monetary Economics 51:277-298.

Basu, Susanto. 1996. "Procyclical Productivity: Increasing Returns or Cyclical Utilization?" The Quarterly Journal of Economics 111 (3): 719-51 (August).

Bénassy, Jean-Pascal. 2004. "Competitiveness, Market Power and Price Stickiness: A Paradox and a Resolution." CEPREMAP.

Bewley, Truman. 1998. "Why not cut pay?" European Economic Review 42:459-490.

Blanchard, Olivier, and Jordi Gali. 2005. "Real Wage Rigidities and the New Keynesian Model." MIT.

—. 2006. “A New Keynesian Model with Unemployment." MIT.

Blanchflower, David G, Andrew J Oswald, and Mario D Garrett. 1990. "Insider Power in Wage Determination." Economica 57 (226): 143-70 (May).

Burnside, Craig, Martin Eichenbaum, and Sergio Rebelo. 1993. "Labor Hoarding and the Business Cycle." Journal of Political Economy 101 (2): 245-73 (April).

Calvo, Guillermo. 1983. "Staggered Prices in a Utility-maximizing Framework." Journal of Monetary Economics 12:383-398.

Canzoneri, Matthew, Robert Cumby, and Behzad Diba. 2004. "The cost of nominal intertia in NNS models." NBER working paper 10889.

Christiano, Lawrence, Martin Eichenbaum, and Charles Evans. 2005. "Nominal Rigidities and the Dynamic Effects of a Shock to Monetary Policy." Journal of Political Economy 113 (1): 1-45.

Christiano, Lawrence J., Martin Eichenbaum, and Robert Vigfusson. 2003, July. "What Happens After a Technology Shock?" Nber working papers 9819, National Bureau of Economic Research, Inc.

Collard, Fabrice, and David de la Croix. 2000. "Gift exchange and the business cycle: the fair wage strikes back." Review of Economic Dynamics 3 (1): 166-193.

Danthine, Jean-Pierre, and John Donaldson. 1990. "Efficiency wages and the business cycle puzzle." European Economic Review 34:1275-1301.

Danthine, Jean-Pierre, and André Kurmann. 2004. "Fair wages in a New Keynesian model of the business cycle." Review of Economic Dynamics 7 (1): 107-142.

_. 2005. "The Macroeconomic Consequences of Reciprocity in Labor Relations." Univ Lausanne.

de la Croix, David, and Philippe Michel. 2002. A Theory of Economic Growth: Dynamics and Policy in Overlapping Generations. Cambridge: Cambridge University Press.

Gali, Jordi, Mark Gertler, and J. David Lopez-Salido. 2001. "European inflation dynamics." European Economic Review 45 (7): 1237-1270. 
2005, May. "Markups, Gaps, and the Welfare Costs of Business Fluctuations." Economics working papers 836, Department of Economics and Business, Universitat Pompeu Fabra.

Kiley, Michael. 1997. "Efficiency wages, nominal rigidities and the cyclical behavior of real wages and marginal cost." Economics Letters 56:215-221.

Levin, Andrew T., Alexei Onatski, John C. Williams, and Noah Williams. 2005, August. "Monetary Policy Under Uncertainty in Micro-Founded Macroeconometric Models." Nber working papers 11523, National Bureau of Economic Research, Inc.

Shapiro, Carl, and Joseph E Stiglitz. 1984. "Equilibrium Unemployment as a Worker Discipline Device." American Economic Review 74 (3): 433-44 (June).

Smets, Frank, and Rafael Wouters. 2003. "An Estimated Dynamic Stochastic General Equilibrium Model of the Euro Area." Journal of the European Economic Association 1 (5): 1123-1175.

. 2005. "Comparing shocks and frictions in US and euro area business cycles: a Bayesian DSGE Approach." Journal of Applied Econometrics 20 (2): 161-183.

- 2006. "Shocks and Frictions in US Business Cycles: A Bayesian DSGE Approach." American Economic Review, p. forthcoming.

Solow, Robert. 1979. "Another possible source of wage stickiness." Journal of Macroeconomics 1:79-82.

Yun, Tack. 1996. "Nominal price rigidity, money supply endogeneity, and business cycles." Journal of Monetary Economics 2-3:345-370. 


\section{A Proof of Proposition 3}

Loglinearizing price equations around the steady state (12) and (14) yield:

$$
\begin{aligned}
& \hat{P}_{t}=\left(1-\xi_{p}\right) \hat{p}_{t}^{\star}+\xi_{p} \hat{P}_{t-1} \\
& \hat{X}_{t}=\left(1-\xi_{p}\right) \hat{p}_{t}^{\star}+\xi_{p} \hat{X}_{t-1}
\end{aligned}
$$

which imply that $\hat{P}_{t}=\hat{X}_{t}$ since their initial conditions are the same.

Loglinearizing the optimal price equation (11) yields:

$$
\begin{aligned}
\frac{(1-\alpha \theta)}{(\alpha(1-\theta))} \hat{p}_{t}^{\star} & =\left(1-\beta \xi_{p}\right) \sum_{s=t}^{\infty}\left(\beta \xi_{p}\right)^{s-t} \mathrm{E}_{t} \frac{\theta}{1-\theta} \hat{P}_{s} \\
& =\left(1-\beta \xi_{p}\right) \sum_{s=t}^{\infty}\left(\beta \xi_{p}\right)^{s-t} \mathrm{E}_{t}\left((1-\psi) \hat{w}_{s}-\hat{Y}_{s}+\frac{1}{\alpha} \hat{Y}_{s}+\frac{1}{\alpha(1-\theta)} \hat{P}_{s}\right)
\end{aligned}
$$

Wages follow (10):

$$
\hat{w}_{t}=\Omega \hat{N}_{t}
$$

Effort follows

$$
\hat{e}=\psi \hat{w}
$$

The output equation leads to:

$$
\alpha\left(\hat{e}_{t}+\hat{N}_{t}\right)=\alpha(1+\psi \Omega) \hat{N}_{t}=\hat{Y}_{t}-\frac{1}{1-\theta}\left(\hat{X}_{t}-\hat{P}_{t}\right)=\hat{Y}_{t}
$$

Hence, the output changes linked to the difference between $\hat{X}_{t}$ and $\hat{P}_{t}$ disappear in the linearized version of the model, reflecting that this discrepancy has only a secondorder effect (stressed in the welfare analysis carried out by Canzoneri, Cumby, and Diba (2004)).

And, finally, the equilibrium on the goods market (15) together with the first-order condition (2) lead to:

$$
\hat{Y}_{t}=\hat{M}_{t}-\hat{P}_{t}
$$

Starting from (22) and replacing $\hat{w}_{s}$ by its value from (23), $\hat{N}_{t}$ by its value from (24), and $\hat{Y}_{t}$ by its value from (25), we get:

$$
\hat{p}_{t}^{\star}=\frac{1-\beta \xi_{p}}{1-\alpha \theta} \sum_{s=t}^{\infty}\left(\beta \xi_{p}\right)^{s-t} \mathrm{E}_{t}\left((1-\theta)\left(1-\alpha+\frac{(1-\psi) \Omega}{\psi \Omega+1}\right)\left(\hat{M}_{s}-\hat{P}_{s}\right)+(1-\alpha \theta) \hat{P}_{s}\right)
$$

This is equivalent to:

$$
\hat{p}_{t}^{\star}=\beta \xi_{p} \mathrm{E}_{t} \hat{p}_{t+1}^{\star}+\frac{1-\beta \xi_{p}}{1-\alpha \theta}\left((1-\theta)\left(1-\alpha+\frac{(1-\psi) \Omega}{\psi \Omega+1}\right)\left(\hat{M}_{t}-\hat{P}_{t}\right)+(1-\alpha \theta) \hat{P}_{t}\right)
$$


We now replace $\hat{p}_{t}^{\star}$ and $\hat{p}_{t+1}^{\star}$ by their value from $(21): \hat{p}_{t}^{\star}=\left(\hat{P}_{t}-\xi_{p} \hat{P}_{t-1}\right) /\left(1-\xi_{p}\right)$ and $\beta \xi_{p} \mathrm{E}_{t} \hat{p}_{t+1}^{\star}=\beta \xi_{p}\left(\mathrm{E}_{t} \hat{P}_{t+1}-\xi_{p} \hat{P}_{t}\right) /\left(1-\xi_{p}\right)$ :

$$
\begin{aligned}
& \left(\hat{P}_{t}-\xi_{p} \hat{P}_{t-1}\right)=\beta \xi_{p}\left(\mathrm{E}_{t} \hat{P}_{t+1}-\xi_{p} \hat{P}_{t}\right) \\
& \quad+\left(1-\xi_{p}\right) \frac{1-\beta \xi_{p}}{1-\alpha \theta}\left((1-\theta)\left(1-\alpha+\frac{(1-\psi) \Omega}{\psi \Omega+1}\right)\left(\hat{M}_{t}-\hat{P}_{t}\right)+(1-\alpha \theta) \hat{P}_{t}\right)
\end{aligned}
$$

which simplifies into:

$$
a_{1}\left(\hat{P}_{t}-\hat{M}_{t}\right)+a_{2}\left(\hat{P}_{t}-\hat{P}_{t-1}\right)+a_{3}\left(\hat{P}_{t}-\mathrm{E}_{t} \hat{P}_{t+1}\right)=0
$$

with

$$
a_{1}=\left(1-\xi_{p}\right) \frac{1-\beta \xi_{p}}{1-\alpha \theta}(1-\theta)\left(1-\alpha+\frac{(1-\psi) \Omega}{\psi \Omega+1}\right), a_{2}=\xi_{p}, a_{3}=\beta \xi_{p} .
$$

Using the method of undetermined coefficients, we can show that the solution is of the form:

$$
\hat{P}_{t}=\rho \hat{P}_{t-1}+\sum_{j=0}^{\infty} b_{j} \mathrm{E}_{t} \hat{M}_{t+j}
$$

i.e. equation (16) of the main text. $\rho$ is the stable root of

$$
R(\rho)=a_{3} \rho^{2}-\left(a_{1}+a_{2}+a_{3}\right) \rho+a_{2}=0 .
$$

If $\psi$ increases, or if $\Omega$ decreases, $a_{1}$ decreases, which raises price stickiness $\rho$ through (26).

\section{B The Loglinearized Model}

There is a large part of the log-linearized benchmark Smets-Wouters model which is not affected by the efficiency wage assumption. The following linearized equations are relevant both for the benchmark Smets and Wouters (2005) New Keynesian model and for its efficiency wage variant developed in this paper. The consumption equation with external habit is given by

$$
\hat{C}_{t}=\frac{1}{1+h}\left(\mathrm{E}_{t} \hat{C}_{t+1}+h \hat{C}_{t-1}\right)-\frac{1-h}{(1+h) \sigma_{c}}\left(\hat{R}_{t}-\mathrm{E}_{t} \hat{\pi}_{t+1}\right)+\frac{1-h}{(1+h) \sigma_{c}}\left(\hat{\varepsilon}_{t}^{b}-\mathrm{E}_{t} \hat{\varepsilon}_{t+1}^{b}\right)
$$

and the investment equation is

$$
\hat{I}_{t}=\frac{1}{1+\beta}\left(\beta \mathrm{E}_{t} \hat{I}_{t+1}+\hat{I}_{t-1}+\varphi\left(\hat{Q}_{t}+\hat{\varepsilon}_{t}^{i}\right)\right)
$$

where $\varphi=1 / \bar{S}^{\prime \prime}$ where $S\left(I_{t} / I_{t-1}\right)$ is the investment adjustment cost function incurred in the case of changes in investment. The corresponding $Q$ equation is given by

$$
\hat{Q}_{t}=\hat{\pi}_{t+1}+\hat{\varepsilon}_{t}^{b} \frac{(1+h) \sigma_{c}}{1-h}-\hat{R}_{t}+(1-\beta(1-\tau)) \mathrm{E}_{t} \hat{r}_{t+1}^{k}+\beta(1-\tau) \mathrm{E}_{t} \hat{Q}_{t+1}
$$


while the capital accumulation equation is

$$
\hat{K}_{t}=(1-\tau) \hat{K}_{t-1}+\tau\left(\hat{I}_{t-1}+(1+\beta) \frac{1}{\varphi} \hat{\varepsilon}_{t-1}^{I}\right)
$$

and the utilized capital is

$$
\hat{\kappa}_{t}=\hat{K}_{t-1}+\vartheta \hat{r}_{t}^{k}
$$

with $\vartheta=\vartheta^{\prime}(1) / \vartheta^{\prime \prime}(1)$, the inverse of the elasticity of the capital utilization cost function. The price equation is log-linearized from the intermediate retailer FOC:

$$
\begin{aligned}
\hat{\pi}_{t} & =\frac{1}{1+\beta \gamma_{p}}\left[\beta \hat{\pi}_{t+1}+\gamma_{p} \hat{\pi}_{t-1}+\frac{\left(1-\xi_{p}\right)\left(1-\beta \xi_{p}\right)}{\xi_{p}\left(1+\beta \gamma_{p}\right)}\left(\hat{z}_{t}+\hat{\varepsilon}_{t}^{p}\right)\right] \\
\text { with } \hat{\varepsilon}_{t}^{p} & =\rho_{p} \hat{\varepsilon}_{t-1}^{p}-\zeta_{p} \eta_{t-1}^{p}+\eta_{t}^{p} \text { and } \eta_{t}^{p} \text { an i.i.d.-Normal error term }
\end{aligned}
$$

The global demand is simply the sum of consumption, investment, the cost incurred when varying capital utilization and government spending which plays actually the role of the residual

$$
\begin{aligned}
\hat{Y}_{t} & =\left(1-\tau k_{y}-g_{y}\right) \hat{C}_{t}+\tau k_{y} \hat{I}_{t}+k_{y}\left(\frac{1}{\beta}+\tau-1\right)+g_{y} \hat{\varepsilon}_{t}^{g} \\
\text { with } \hat{\varepsilon}_{t}^{g} & =\rho_{g} \hat{\varepsilon}_{t-1}^{g}+\eta_{t}^{g} \text { and } \eta_{t}^{g} \text { an i.i.d.-Normal error term }
\end{aligned}
$$

with $k_{y}$ the steady state capital output ratio, $g_{y}$ the steady-state government spendingoutput ratio.

The equations relating to the production sector of the model are clearly affected by the efficiency wage assumption. However, for the four following expressions, the benchmark Smets and Wouters (2005) linearized model and its efficiency wage are only differentiated by the presence of the effort variable $\hat{e}_{t}$. We only report the linearized expressions for the efficiency wage variant.

Log-linearizing and averaging the production function of the intermediate retailer firms, one obtains

$$
\begin{aligned}
\hat{Y}_{t} & =\phi\left(\alpha \cdot\left(\hat{e}_{t}+\hat{N}_{t}\right)+(1-\alpha) \hat{\kappa}_{t}+\hat{\varepsilon}_{t}^{a}\right) \\
\text { with } \hat{\varepsilon}_{t}^{a} & =\rho_{a} \hat{\varepsilon}_{t-1}^{a}+\eta_{t}^{a} \text { and } \eta_{t}^{a} \text { an i.i.d.-Normal error term }
\end{aligned}
$$

As discussed in section 2.2.3, all the intermediate producers share the same wage per efficient unit of labor and the same capital-efficient labor ratio. Therefore, the labor demand of the firms is log-linearized as

$$
\hat{w}_{t}-\hat{e}_{t}=\hat{z}_{t}+(1-\alpha)\left(\hat{\kappa}_{t}-\hat{N}_{t}-\hat{e}_{t}\right)+\hat{\varepsilon}_{t}^{a}
$$

while the demand of capital is:

$$
\hat{r}_{t}^{k}=\hat{z}_{t}-\alpha\left(\hat{\kappa}_{t}-\hat{N}_{t}-\hat{e}_{t}\right)+\hat{\varepsilon}_{t}^{a}
$$


The marginal cost equation writes down as

$$
\hat{z}_{t}=\alpha \cdot\left(\hat{w}_{t}-\hat{e}_{t}\right)+(1-\alpha) \cdot \hat{r}_{t}^{k}-\hat{\varepsilon}_{t}^{a}
$$

As expected, the wage equation is the most different one in the benchmark SmetsWouters like model and its efficiency wage variant. Under efficiency wage, the real wage equation after loglinearization is

$$
\begin{aligned}
\hat{w}_{t} & =\frac{1}{(1+\beta)}\left[\beta \mathrm{E}_{t} \hat{w}_{t+1}+\tau \hat{w}_{t-1}+\beta \mathrm{E}_{t} \hat{\pi}_{t+1}+\gamma_{w} \hat{\pi}_{t-1}-\left(1+\beta \gamma_{w}\right) \hat{\pi}_{t}\right] \\
& +\frac{\left(1-\beta \xi_{w}\right)\left(1-\xi_{w}\right)}{\xi_{w}(1+\beta)(1-\psi)}\left[\hat{\varepsilon}_{t}^{a}+\hat{z}_{t}-(1-\alpha)\left(\hat{e}_{t}+\hat{N}_{t}-\hat{\kappa}_{t}\right)-(1-\psi) \hat{w}_{t}\right]
\end{aligned}
$$

instead of

$$
\begin{aligned}
\hat{w}_{t} & =\frac{1}{(1+\beta)}\left[\beta \mathrm{E}_{t} \hat{w}_{t+1}+\hat{w}_{t-1}+\beta \mathrm{E}_{t} \hat{\pi}_{t+1}+\gamma_{w} \hat{\pi}_{t-1}-\left(1+\beta \gamma_{w}\right) \hat{\pi}_{t}\right] \\
& +\frac{\left(1-\beta \xi_{w}\right)\left(1-\xi_{w}\right)}{\xi_{w}(1+\beta)}\left[\sigma_{l} \hat{N}_{t}+\frac{1}{1-h}\left(\hat{C}_{t}-\hat{C}_{t-1}\right)-\hat{w}_{t}+\hat{\varepsilon}_{t}^{w}\right]
\end{aligned}
$$

in the benchmark model. One can note that, from the labor demand equation, the term into square brackets in expression (27a) can be re-written as

$$
\left[\varepsilon_{t}^{a}+\hat{z}_{t}-(1-\alpha)\left(\hat{e}_{t}+\hat{N}_{t}-\hat{\kappa}_{t}\right)-(1-\psi) \hat{w}_{t}\right]=\hat{w}_{t} \psi-\hat{e}_{t}
$$

and the RHS corresponds exactly to the log-linearized modified Solow condition (7). This means that the Solow condition holds in the long run or if $\xi_{w}$ becomes close to zero. In comparison to the wage equation of the benchmark model, we also remark that the wage markup shock $\hat{\varepsilon}_{t}^{w}$ is now replaced by the effort shock $\hat{\varepsilon}_{t}^{e f}$, both being $\operatorname{ARMA}(1,1)$ processes.

After linearization and averaging, the log-linearized effort in the efficiency wage version of the model equation writes down as

$$
\hat{e}_{t}=\hat{w}_{t} \cdot\left(1-\phi_{3}\right)-\hat{N}_{t} \cdot \phi_{2}^{\prime}+\hat{\varepsilon}_{t}^{e f}
$$

with

$$
\phi_{2}^{\prime}=\phi_{2} \cdot \frac{N}{1-N}\left(\frac{1}{(1-N) w}\right)^{\psi}
$$

where $N$ is the steady state employment rate and $w$ the steady-state wage which is equal to $\left[\theta(1-\alpha)\left(\theta \alpha / r^{k}\right)^{\frac{\alpha}{1-\alpha}}\right]$ when steady-state effort is fixed at 1 . Finally, the model is closed by the following empirical monetary policy reaction function

$$
\begin{aligned}
\hat{R}_{t} & =\rho \cdot\left(\hat{R}_{t-1}\right)+(1-\rho)\left[r_{\pi} \hat{\pi}_{t}+r_{y}\left(\hat{Y}_{t}-\hat{Y}_{t}^{p}\right)\right] \\
& +r_{\Delta y}\left[\left(\hat{Y}_{t}-\hat{Y}_{t}^{p}\right)-\left(\hat{Y}_{t-1}-\hat{Y}_{t-1}^{p}\right)\right]+\hat{\varepsilon}_{t}^{r}
\end{aligned}
$$

with $\hat{\varepsilon}_{t}^{r}=\rho_{r} \hat{\varepsilon}_{t-1}^{r}+\eta_{t}^{r}$ and $\eta_{t}^{r}$ an i.i.d.-Normal error term 


\section{B.1 Loglinearizing the Wage Equation}

Given the objective equation (19), we may compute the FOC for a maximum:

$$
\begin{aligned}
& \mathrm{E}_{t} \sum_{s=0}^{\infty}\left(\beta \xi_{w}\right)^{s} \frac{\lambda_{t+s}}{\lambda_{t}} \frac{1}{P_{t+s}}\left[Z_{t+s} \frac{q_{t+s}(j)}{e_{t+s}(j)} \alpha \phi_{1} \frac{\left(\frac{W_{t}^{\star}(j)}{P_{t}} \Pi_{l=0}^{s-1} \pi_{t+l}^{\gamma_{w}} \cdot \bar{\pi}^{1-\gamma_{w}}\right)^{\psi}}{W_{t}^{\star}(j)}\right. \\
& \left.-n_{t+s}(j) \cdot \Pi_{l=0}^{s-1} \pi_{t+l}^{\gamma_{w}} \cdot \bar{\pi}^{1-\gamma_{w}}\right]=0
\end{aligned}
$$

Loglinearizing this FOC around the steady state, we get

$$
\begin{aligned}
(1-\psi) \hat{W}_{t}^{\star}(j)= & \left(1-\beta \xi_{w}\right) \cdot \sum_{s=0}^{\infty}\left(\beta \xi_{w}\right)^{s} \mathrm{E}_{t}\left[\varepsilon_{t+s}^{a}+\hat{Z}_{t+s}\right. \\
& \left.-(1-\alpha)\left(\hat{e}_{t+s}(j)+\hat{n}_{t+s}(j)-\hat{\kappa}_{t+s}(j)\right)-\psi \hat{P}_{t}-(1-\psi) \sum_{l=0}^{s-1} \gamma_{w} \hat{\pi}_{t+l}\right]
\end{aligned}
$$

We know that the capital-efficient labor ratio is not firm-specific and therefore drop the $j$ index in the optimal wage equation. The latter expression may be re-written as

$$
\begin{aligned}
(1-\psi) \hat{W}_{t}^{\star}=\left(1-\beta \xi_{w}\right) \cdot\left[\varepsilon_{t}^{a}+\hat{Z}_{t}-(1-\alpha)\left(\hat{e}_{t}+\hat{n}_{t}-\hat{\kappa}_{t}\right)-\psi \hat{P}_{t}\right] & \\
& +\beta \xi_{w}(1-\psi)\left(\hat{W}_{t+1}^{\star}-\gamma_{w} \hat{\pi}_{t}\right)
\end{aligned}
$$

Log-linearising expression (20) around steady state, one obtains that

$$
\hat{W}_{t}^{\star}=\frac{\hat{W}_{t}-\xi_{w} \hat{W}_{t-1}-\gamma_{w} \xi_{w} \hat{\pi}_{t-1}}{1-\xi_{w}}
$$

Substituting for $\hat{W}_{t}^{\star}$ in the optimal wage expression, we obtain after transformations

$$
\begin{aligned}
\hat{w}_{t} & =\frac{\beta}{1+\beta} \hat{w}_{t+1}+\frac{1}{1+\beta} \hat{w}_{t-1}+\frac{\beta}{1+\beta} \hat{\pi}_{t+1} \\
& +\frac{\gamma_{w}}{1+\beta} \hat{\pi}_{t-1}-\frac{1+\beta \gamma_{w}}{1+\beta} \hat{\pi}_{t} \\
& +\frac{\left(1-\beta \xi_{w}\right)\left(1-\xi_{w}\right)}{(1-\psi) \xi_{w}(1+\beta)}\left[\varepsilon_{t}^{a}+\hat{z}_{t}-(1-\alpha)\left(\hat{e}_{t}+\hat{N}_{t}-\hat{\kappa}_{t}\right)-(1-\psi) \hat{w}_{t}\right]
\end{aligned}
$$

where $\hat{w}_{t}$ and $\hat{z}_{t}$ are the real wage and real marginal cost in deviation from steady state. 


\section{B.2 Variants to the Effort Function}

We consider here how the introduction of a reference to lagged wage and to labor productivity affects the model and its loglinearized form. Let us introduce these two further arguments in our model so that the effort function becomes

$$
\begin{aligned}
e_{t}(i)=\frac{\phi_{1}}{\psi}\left(w_{t}(i)^{\psi}-\phi_{2}(\right. & \left.\frac{1}{1-N_{t}}\right)^{\psi}-\phi_{3} w_{t}^{\psi} \\
& \left.-\phi_{4} w_{t-1}^{\psi}-\phi_{5}\left(\frac{q_{t}(i)}{n_{t}(i)}\right)^{\psi}-\left(\phi_{0}-\phi_{2}-\phi_{3}-\phi_{4}-\phi_{5}\right)\right)
\end{aligned}
$$

The introduction of productivity in the effort function affects the labor demand by the intermediate producers. It is now given by

$$
n_{t}(i)=z_{t}(1-\alpha) \frac{q_{t}(i)}{w_{t}(i) e_{t}(i)}\left[e_{t}(i)+\phi_{1} \phi_{5}\left(\frac{q_{t}(i)}{n_{t}(i)}\right)^{\psi}\right]
$$

This is the only relation that is modified. For the rest, the FOC for capital and for wage are left unchanged. We can easily check that all the firms resetting their wage at the same period will choose the same price. Indeed, given the competitive market assumption all the firms face the same marginal cost

$$
z_{t}=\frac{1}{\varepsilon_{t}^{a}} \cdot\left(\frac{w_{t}(i)}{e_{t}(i)+n_{t}(i) \frac{\partial e_{t}(i)}{\partial n_{t}(i)}}\right)^{\alpha}\left(r_{t}^{k}\right)^{1-\alpha} \alpha^{-\alpha}(1-\alpha)^{-(1-\alpha)}
$$

From this expression we conclude that $\frac{w_{t}(i)}{e_{t}(i)+n_{t}(i) \frac{\partial e_{t}(i)}{\partial n_{t}(i)}}$ is not firm specific. Combining this information with the expression for labor demand, we can conclude that, as in the initial efficiency wage model, all the firms share the same productivity per efficient unit, which is enough to prove that intermediate producers setting wage at time $t$ will behave similarly.

Note that combining the labor demand by the firms (30) with their optimal wage (28) for $\xi_{w} \rightarrow 0$, we obtain that

$$
\begin{aligned}
e_{t}(i) & =\frac{\partial e}{\partial w(i)} w(i)-\frac{\partial e}{\partial n(i)} n(i) \\
& =\phi_{1} w_{t}(i)^{\psi}-\phi_{1} \phi_{5}\left(\frac{q_{t}(i)}{n_{t}(i)}\right)^{\psi}
\end{aligned}
$$

which Danthine and Kurmann (2005) denote as a modified Solow condition.

The linearized labor demand (30) expression is

$$
\begin{aligned}
\hat{w}_{t}= & \hat{z}_{t}+(1-\alpha)\left(\kappa_{t}-\hat{N}_{t}-\hat{e}_{t}\right)\left(1+\psi \phi_{5}\left(\frac{q}{N w}\right)^{\psi}\right) \\
& +\hat{e}_{t}\left[1-(1-\psi) \phi_{5}\left(\frac{q}{N w}\right)^{\psi}\right]+\hat{\varepsilon}_{t}^{a}
\end{aligned}
$$


Loglinearizing the effort equation (29) yields

$$
\begin{aligned}
\hat{e}_{t}\left(1-\phi_{5}\left(\frac{q}{N w}\right)^{\psi}\right)= & \hat{w}_{t}\left(1-\phi_{3}\right)-\hat{N}_{t} \phi_{2}\left(\frac{1}{(1-N) w}\right)^{\psi} \frac{N}{1-N}-\hat{w}_{t-1} \phi_{4} \\
& -\left(\hat{q}_{t}-\hat{N}_{t}\right) \phi_{5}\left(\frac{q}{N w}\right)^{\psi}+\hat{\varepsilon}_{t}^{e f}
\end{aligned}
$$

where the steady state employment, wage and production appears. The FOC conditions for labor and for wage in steady state are

$$
\begin{aligned}
z \alpha \frac{q}{N e}\left[e+\phi_{1} \phi_{5}\left(\frac{q}{N}\right)^{\psi}\right] & =w \\
z \alpha \frac{q}{N e} \phi_{1} w^{\psi} & =w
\end{aligned}
$$

from which we obtain the modified Solow condition

$$
\begin{aligned}
e & =\frac{\partial e}{\partial w(i)} w(i)-\frac{\partial e}{\partial n(i)} n(i) \\
& =\phi_{1} w^{\psi}-\phi_{1} \phi_{5}(q / N)^{\psi}
\end{aligned}
$$

Given that the steady state real return on capital is

$$
r^{k}=z(1-\alpha) \frac{q}{\kappa}=\frac{1}{\beta}+\tau-1
$$

and that the steady state productivity per efficient labor unit is

$$
\frac{q}{N e}=\left(\frac{z(1-\alpha)}{r^{k}}\right)^{\frac{1-\alpha}{\alpha}}
$$

we obtain an expression for steady state wage

$$
w^{\psi}=\left[z \alpha\left(\frac{z(1-\alpha)}{r^{k}}\right)^{\frac{1-\alpha}{\alpha}} \phi_{1}\right]^{\frac{\psi}{1-\psi}}
$$

Restricting effort level to be positive and equal to unity in steady state yields that the steady state wage and $\phi_{1}$ are determined by the solution of the two equations system in two unknowns formed by the wage expression above and the modified Solow condition.

\section{Estimation Results}

A limited number of structural parameters, which are very poorly identified by our estimation strategy, are fixed at standard values. The discount factor is fixed at 0.99 to reflect an average annual real rate of $4 \%$, the capital share in the Cobb-Douglas production function is set at 0.24 , the quarterly depreciation rate is fixed at 0.025 per quarter. The share of steady-state consumption in total output is assumed to be 0.65 while the share of steady-state investment is set to 0.17 . The parameter capturing the markup in wage setting is set to 0.5 in the benchmark standard New Keynesian model. 
Table 1: Estimation Results: Benchmark vs Efficient Wage

\begin{tabular}{|c|c|c|c|c|c|c|c|c|}
\hline & & \multicolumn{3}{|c|}{ prior } & \multicolumn{2}{|c|}{ benchmark } & \multicolumn{2}{|c|}{ eff. wage } \\
\hline & & distrib. & mean & s.e. & mode & s.e. & mode & s. e. \\
\hline \multirow[t]{5}{*}{ effort } & $\psi$ & beta & 0.500 & 0.150 & & & 0.358 & 0.077 \\
\hline & $\phi_{2}^{\prime}$ & norm & 0.500 & 0.150 & & & 0.182 & 0.084 \\
\hline & $\phi_{3}$ & norm & 0.500 & 0.150 & & & 0.795 & 0.089 \\
\hline & $\phi_{4}$ & norm & 0.500 & 0.150 & & & 0.000 & - \\
\hline & $\phi_{5}$ & norm & 0.500 & 0.150 & & & 0.000 & - \\
\hline \multirow[t]{11}{*}{ other param } & invest. adj. cost. & norm & 4.000 & 1.500 & 7.397 & 0.983 & 5.590 & 1.038 \\
\hline & sig. cons. utility & norm & 1.000 & 0.375 & 1.161 & 0.122 & 1.755 & 0.255 \\
\hline & habit & beta & 0.700 & 0.100 & 0.771 & 0.034 & 0.445 & 0.064 \\
\hline & calvo wage & beta & 0.750 & 0.050 & 0.773 & 0.041 & 0.780 & 0.045 \\
\hline & sig. labor utility & norm & 2.000 & 0.750 & 2.920 & 0.577 & & \\
\hline & calvo price & beta & 0.750 & 0.050 & 0.902 & 0.020 & 0.892 & 0.016 \\
\hline & index. wage & beta & 0.500 & 0.150 & 0.398 & 0.125 & 0.427 & 0.114 \\
\hline & index. & beta & 0.500 & 0.150 & 0.135 & 0.061 & 0.144 & 0.074 \\
\hline & calvo & beta & 0.500 & 0.150 & 0.787 & 0.019 & 0.822 & 0.019 \\
\hline & il. adj. cost & norm & 0.300 & 0.100 & 0.432 & 0.089 & 0.357 & 0.096 \\
\hline & fixed cost $1+\Phi / Y$ & norm & 1.250 & 0.125 & 1.440 & 0.090 & 1.288 & 0.105 \\
\hline \multirow[t]{4}{*}{ Taylor rule } & $\mathrm{r}$ inflation & norm & 1.500 & 0.250 & 1.648 & 0.185 & 1.705 & 0.151 \\
\hline & r lagged int. rate & beta & 0.750 & 0.100 & 0.915 & 0.016 & 0.886 & 0.016 \\
\hline & r output-gap & norm & 0.125 & 0.050 & 0.153 & 0.037 & 0.206 & 0.036 \\
\hline & $\mathrm{rd}(\mathrm{o}$ & norm & 0.125 & 0.050 & 0.147 & 0.025 & 0.164 & 0.028 \\
\hline \multirow[t]{4}{*}{ Constants } & inflat & norm & 0.625 & 0.100 & 0.644 & 0.100 & 0.616 & 0.097 \\
\hline & int. rate & norm & 0.625 & 0.100 & 0.618 & 0.080 & 0.610 & 0.084 \\
\hline & labor & norm & 0.100 & 0.100 & 0.067 & 0.015 & 0.101 & 0.023 \\
\hline & trend & norm & 0.400 & 0.100 & 0.328 & 0.076 & 0.554 & 0.023 \\
\hline \multirow[t]{7}{*}{ shocks: AR } & productivity & beta & 0.750 & 0.150 & 0.999 & 0.001 & 0.997 & 0.003 \\
\hline & risk premium & beta & 0.750 & 0.150 & 0.717 & 0.058 & 0.873 & 0.034 \\
\hline & & beta & 0.750 & 0.150 & 0.998 & 0.002 & 0.997 & 0.002 \\
\hline & investment & beta & 0.750 & 0.150 & 0.910 & 0.038 & 0.934 & 0.021 \\
\hline & intere & beta & 0.750 & 0.150 & 0.405 & 0.074 & 0.301 & 0.068 \\
\hline & price markup & beta & 0.750 & 0.150 & 0.963 & 0.033 & 0.767 & 0.065 \\
\hline & wage m-up/effort & beta & 0.750 & 0.150 & 0.961 & 0.012 & 0.968 & 0.012 \\
\hline \multirow[t]{3}{*}{ shocks: MA } & investment & beta & 0.750 & 0.150 & 0.887 & 0.065 & 0.863 & 0.039 \\
\hline & price markup & beta & 0.750 & 0.150 & 0.863 & 0.038 & 0.597 & 0.116 \\
\hline & wage m-up/effort & beta & 0.750 & 0.150 & 0.863 & 0.045 & 0.947 & 0.017 \\
\hline shocks: CO & $\rho_{a g}$ & norm & 0.200 & 0.100 & 0.142 & 0.037 & 0.219 & 0.046 \\
\hline \multirow[t]{7}{*}{ shocks: SE } & productivity & invg & 0.100 & 2.000 & 0.778 & 0.099 & 0.613 & 0.080 \\
\hline & risk premium & invg & 0.100 & 2.000 & 0.102 & 0.016 & 0.077 & 0.012 \\
\hline & gov. spending & invg & 0.100 & 2.000 & 0.331 & 0.021 & 0.312 & 0.019 \\
\hline & investment & invg & 0.100 & 2.000 & 0.567 & 0.045 & 0.534 & 0.047 \\
\hline & interest rate & invg & 0.100 & 2.000 & 0.146 & 0.011 & 0.152 & 0.011 \\
\hline & price markup & invg & 0.100 & 2.000 & 0.154 & 0.027 & 0.191 & 0.024 \\
\hline & wage m-up/effort & invg & 0.100 & 2.000 & 0.160 & 0.021 & 0.184 & 0.019 \\
\hline \multirow{2}{*}{\multicolumn{2}{|c|}{$\begin{array}{l}\text { Log data density } \\
\text { posterior mode }\end{array}$}} & & & & \multicolumn{2}{|c|}{-440.425} & \multicolumn{2}{|c|}{-432.321} \\
\hline & & & & & \multicolumn{2}{|c|}{345.032} & \multicolumn{2}{|c|}{328.781} \\
\hline
\end{tabular}


Table 2: Estimation Results: Alternative Specifications

\begin{tabular}{|c|c|c|c|c|c|}
\hline & \multicolumn{2}{|c|}{ eff. Wage $\phi_{4}>0$} & \multicolumn{2}{|c|}{ eff. Wage $\phi_{5}>0$} \\
\hline & & mode & std. dev. & mode & std. dev. \\
\hline \multirow[t]{5}{*}{ effort } & $\psi$ & 0.364 & 0.074 & 0.350 & 0.093 \\
\hline & $\phi_{2}^{\prime}$ & 0.182 & 0.074 & 0.197 & 0.081 \\
\hline & $\phi_{3}$ & 0.790 & 0.082 & 0.700 & 0.088 \\
\hline & $\phi_{4}$ & -0.012 & 0.007 & 0.000 & - \\
\hline & $\phi_{5}$ & 0.000 & - & 0.125 & 0.060 \\
\hline \multirow[t]{10}{*}{ other param } & invest. adj. cost. & 5.637 & 1.016 & 5.217 & 1.060 \\
\hline & sig. cons. utility & 1.678 & 0.252 & 1.661 & 0.256 \\
\hline & habit & 0.466 & 0.063 & 0.451 & 0.063 \\
\hline & calvo wage & 0.783 & 0.043 & 0.782 & 0.039 \\
\hline & calvo price & 0.897 & 0.016 & 0.928 & 0.015 \\
\hline & index. wage & 0.426 & 0.111 & 0.372 & 0.111 \\
\hline & index. price & 0.144 & 0.064 & 0.142 & 0.067 \\
\hline & calvo empl. & 0.824 & 0.018 & 0.851 & 0.020 \\
\hline & cap. util. adj. cost & 0.349 & 0.095 & 0.333 & 0.097 \\
\hline & fixed cost $1+\Phi / Y$ & 1.250 & 0.104 & 1.355 & 0.110 \\
\hline \multirow[t]{4}{*}{ Taylor rule } & r inflation & 1.674 & 0.154 & 1.346 & 0.196 \\
\hline & r lagged int. rate & 0.888 & 0.016 & 0.875 & 0.020 \\
\hline & r output-gap & 0.210 & 0.035 & 0.241 & 0.036 \\
\hline & r d(output-gap) & 0.170 & 0.027 & 0.156 & 0.029 \\
\hline \multirow[t]{4}{*}{ Constants } & inflation & 0.620 & 0.097 & 0.610 & 0.097 \\
\hline & int. rate & 0.608 & 0.085 & 0.627 & 0.087 \\
\hline & labor & -0.093 & 0.026 & 0.056 & 0.032 \\
\hline & trend & 0.566 & 0.025 & 0.547 & 0.019 \\
\hline \multirow[t]{7}{*}{ shocks: AR } & productivity & 0.996 & 0.003 & 0.995 & 0.005 \\
\hline & risk premium & 0.877 & 0.033 & 0.887 & 0.038 \\
\hline & gov. spending & 0.998 & 0.002 & 0.998 & 0.002 \\
\hline & investment & 0.933 & 0.020 & 0.937 & 0.020 \\
\hline & interest rate & 0.297 & 0.066 & 0.313 & 0.069 \\
\hline & price markup & 0.777 & 0.064 & 0.821 & 0.073 \\
\hline & wage m-up/effort & 0.965 & 0.013 & 0.966 & 0.011 \\
\hline \multirow[t]{3}{*}{ shocks: MA } & investment & 0.861 & 0.038 & 0.834 & 0.041 \\
\hline & price markup & 0.620 & 0.110 & 0.726 & 0.111 \\
\hline & wage m-up/effort & 0.940 & 0.021 & 0.941 & 0.020 \\
\hline shocks: CO & $\rho_{a g}$ & 0.214 & 0.044 & 0.198 & 0.040 \\
\hline \multirow[t]{7}{*}{ shocks: SE } & productivity & 0.649 & 0.084 & 0.685 & 0.096 \\
\hline & risk premium & 0.074 & 0.011 & 0.077 & 0.012 \\
\hline & gov. spending & 0.311 & 0.019 & 0.311 & 0.019 \\
\hline & investment & 0.534 & 0.046 & 0.513 & 0.044 \\
\hline & interest rate & 0.152 & 0.011 & 0.149 & 0.011 \\
\hline & price markup & 0.189 & 0.023 & 0.190 & 0.022 \\
\hline & wage m-up/effort & 0.180 & 0.020 & 0.188 & 0.019 \\
\hline \multirow{2}{*}{\multicolumn{2}{|c|}{$\begin{array}{l}\text { Log data density } \\
\text { posterior mode }\end{array}$}} & & -439.371 & & -429.441 \\
\hline & & & 331.376 & & 325.028 \\
\hline
\end{tabular}


Table 3: Estimation Results: Alternative Specifications

\begin{tabular}{|c|c|c|c|c|c|}
\hline & \multicolumn{2}{|c|}{ eff. Wage $\phi_{3}=1$} & \multicolumn{2}{|c|}{ eff. Wage diff. prior } \\
\hline & & mode & std. dev. & mode & std. dev. \\
\hline \multirow[t]{5}{*}{ effort } & $\psi$ & 0.234 & 0.061 & 0.305 & 0.001 \\
\hline & $\phi_{2}^{\prime}$ & 0.287 & 0.073 & 0.007 & 0.005 \\
\hline & $\phi_{3}$ & 1.000 & - & 0.701 & 0.005 \\
\hline & $\phi_{4}$ & 0.000 & - & 0.000 & - \\
\hline & $\phi_{5}$ & 0.000 & - & 0.000 & - \\
\hline \multirow[t]{10}{*}{ other param } & invest. adj. cost. & 5.506 & 0.999 & 5.608 & 1.001 \\
\hline & sig. cons. utility & 1.810 & 0.253 & 1.693 & 0.243 \\
\hline & habit & 0.444 & 0.066 & 0.457 & 0.063 \\
\hline & calvo wage & 0.807 & 0.032 & 0.295 & 0.068 \\
\hline & calvo price & 0.883 & 0.018 & 0.896 & 0.018 \\
\hline & index. wage & 0.480 & 0.115 & 0.403 & 0.109 \\
\hline & index. price & 0.120 & 0.055 & 0.148 & 0.067 \\
\hline & calvo empl. & 0.829 & 0.017 & 0.818 & 0.021 \\
\hline & cap. util. adj. cost & 0.370 & 0.094 & 0.340 & 0.092 \\
\hline & fixed cost $1+\Phi / Y$ & 1.343 & 0.102 & 1.225 & 0.100 \\
\hline \multirow[t]{4}{*}{ Taylor rule } & $\mathrm{r}$ inflation & 1.735 & 0.150 & 1.690 & 0.158 \\
\hline & r lagged int. rate & 0.885 & 0.017 & 0.888 & 0.016 \\
\hline & r output-gap & 0.205 & 0.037 & 0.204 & 0.035 \\
\hline & r d(output-gap) & 0.160 & 0.027 & 0.166 & 0.028 \\
\hline \multirow[t]{4}{*}{ Constants } & inflation & 0.613 & 0.097 & 0.617 & 0.097 \\
\hline & int. rate & 0.609 & 0.082 & 0.611 & 0.085 \\
\hline & labor & 0.099 & 0.028 & 0.096 & 0.024 \\
\hline & trend & 0.570 & 0.024 & 0.551 & 0.022 \\
\hline \multirow[t]{7}{*}{ shocks: AR } & productivity & 0.997 & 0.002 & 0.997 & 0.003 \\
\hline & risk premium & 0.853 & 0.036 & 0.877 & 0.035 \\
\hline & gov. spending & 0.997 & 0.002 & 0.998 & 0.002 \\
\hline & investment & 0.940 & 0.022 & 0.935 & 0.021 \\
\hline & interest rate & 0.307 & 0.068 & 0.298 & 0.067 \\
\hline & price markup & 0.795 & 0.062 & 0.767 & 0.065 \\
\hline & wage m-up/effort & 0.965 & 0.018 & 0.966 & 0.012 \\
\hline \multirow[t]{3}{*}{ shocks: MA } & investment & 0.880 & 0.037 & 0.856 & 0.041 \\
\hline & price markup & 0.591 & 0.111 & 0.606 & 0.112 \\
\hline & wage m-up/effort & 0.940 & 0.026 & 0.945 & 0.017 \\
\hline shocks: CO & $\rho_{a g}$ & 0.218 & 0.045 & 0.197 & 0.039 \\
\hline \multirow[t]{7}{*}{ shocks: SE } & productivity & 0.629 & 0.079 & 0.672 & 0.078 \\
\hline & risk premium & 0.081 & 0.012 & 0.076 & 0.012 \\
\hline & gov. spending & 0.314 & 0.020 & 0.313 & 0.019 \\
\hline & investment & 0.543 & 0.048 & 0.525 & 0.046 \\
\hline & interest rate & 0.152 & 0.011 & 0.152 & 0.011 \\
\hline & price markup & 0.181 & 0.023 & 0.193 & 0.022 \\
\hline & wage m-up/effort & 0.182 & 0.021 & 0.183 & 0.019 \\
\hline \multirow{2}{*}{\multicolumn{2}{|c|}{$\begin{array}{l}\text { Log data density } \\
\text { posterior mode }\end{array}$}} & & -428.651 & & -444.848 \\
\hline & & & 327.397 & & 331.174 \\
\hline
\end{tabular}




\section{Impulse Response Functions}

The impulse response functions are calculated for a one standard error shock and with the model parameters evaluated at the mode of the posterior distribution. 
Figure 3: Estimated impulse response function for the monetary policy shock

GDP

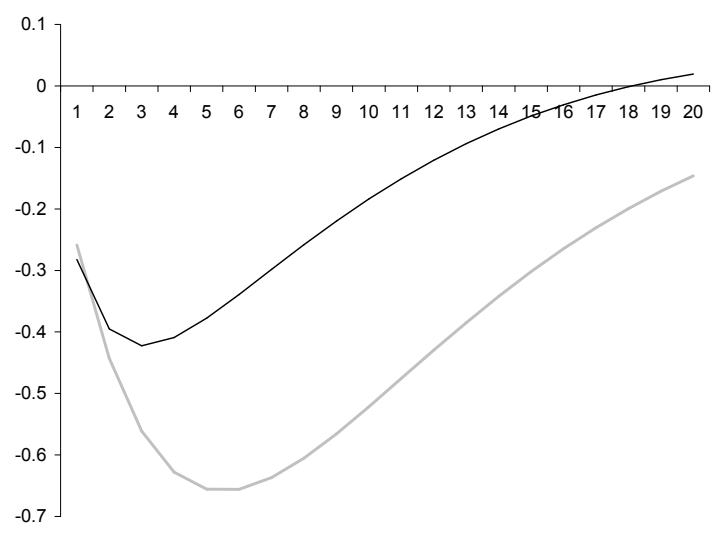

employment

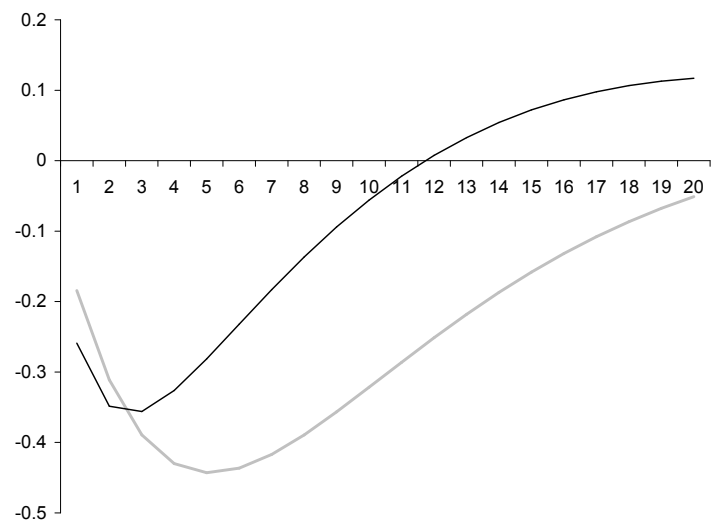

nom. int. rate

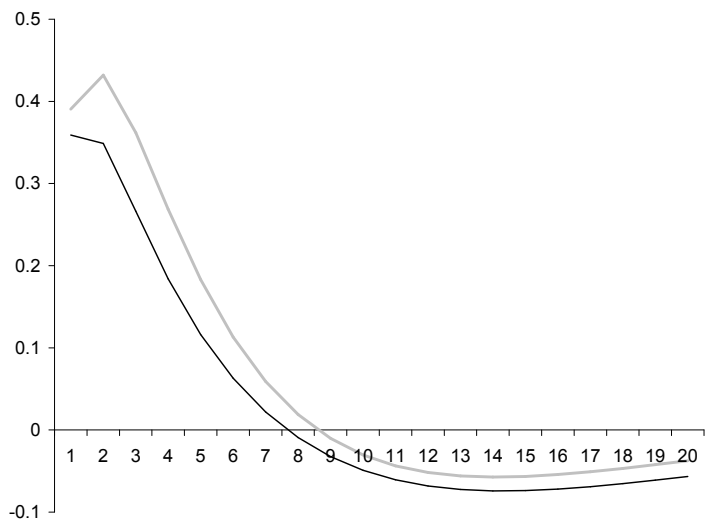

real wage

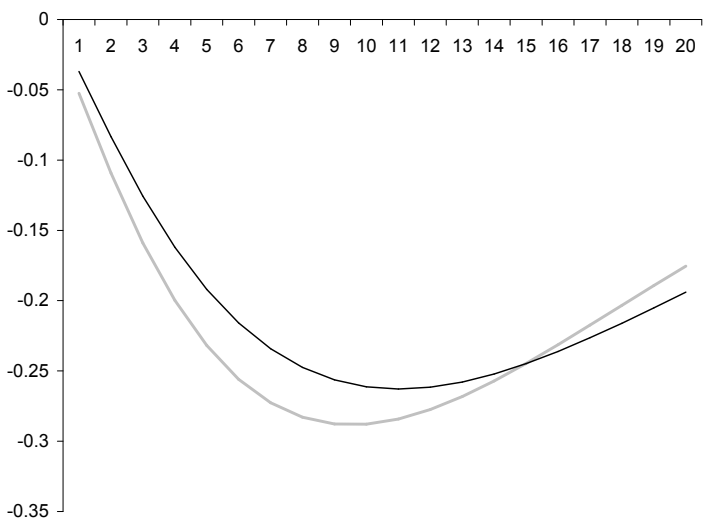

effort

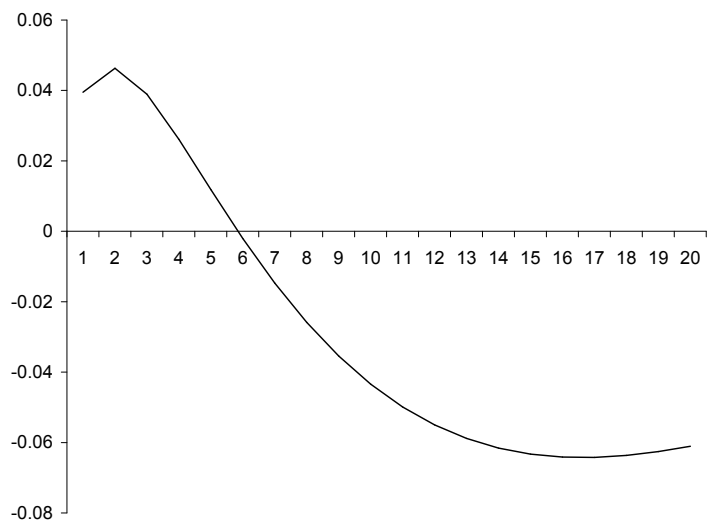

inflation

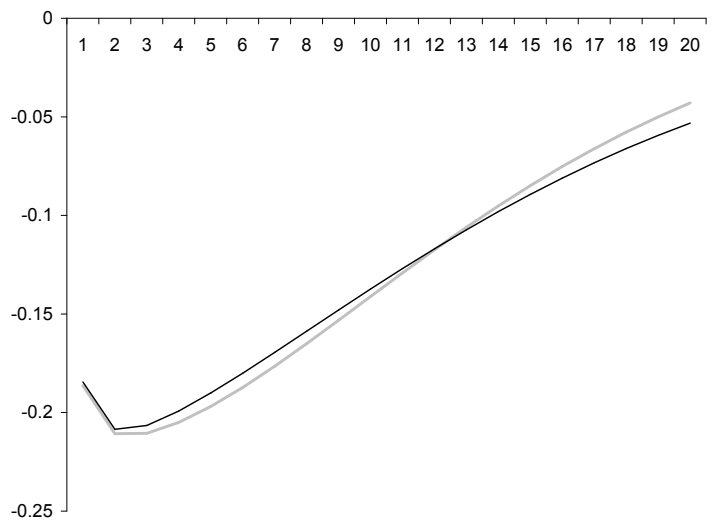

Note: Grey line: benchmark model. Black line: Fair wage model. 
Figure 4: Estimated impulse response function for the total factor productivity shock

GDP

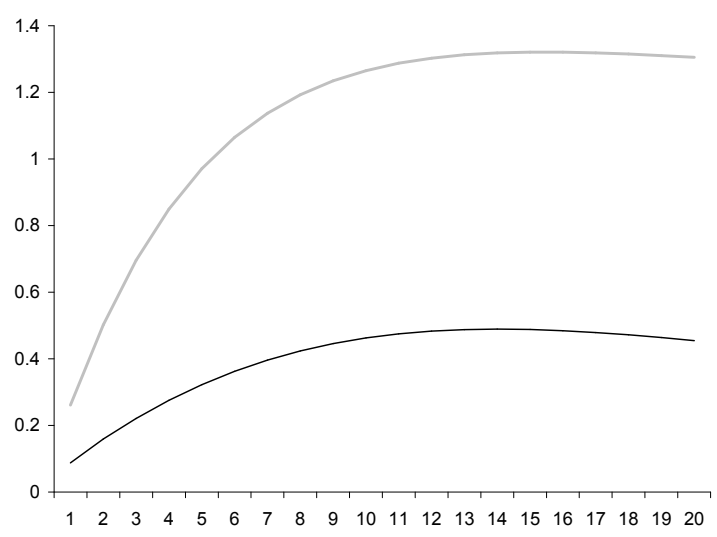

employment

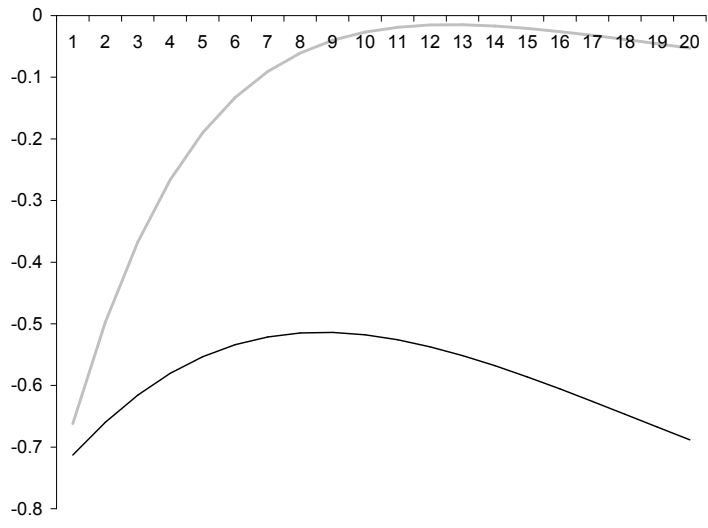

nom. int. rate

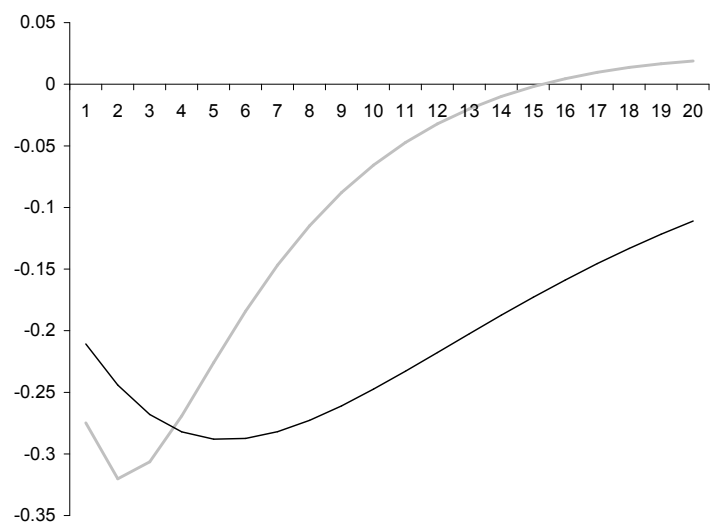

real wage

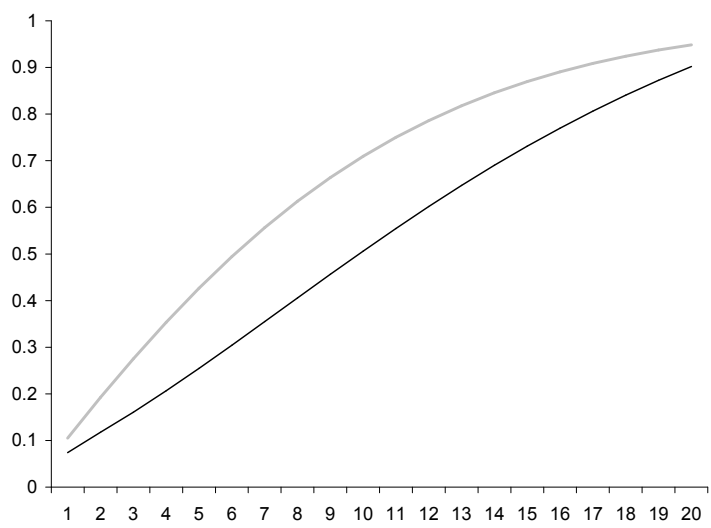

effort

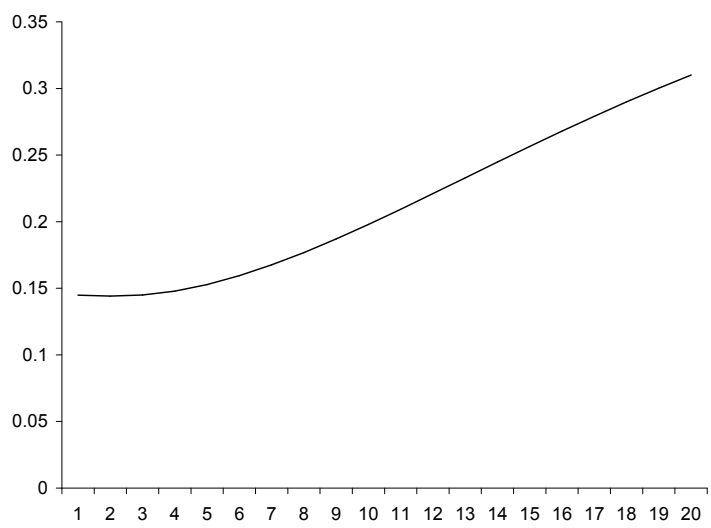

inflation

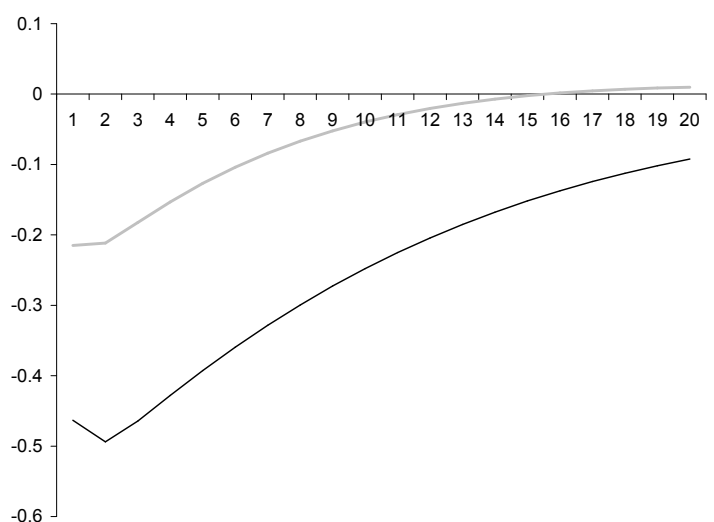

Note: Grey line: benchmark model. Black line: Fair wage model. 
Figure 5: Estimated impulse response function for the wage markup and effort shock

GDP

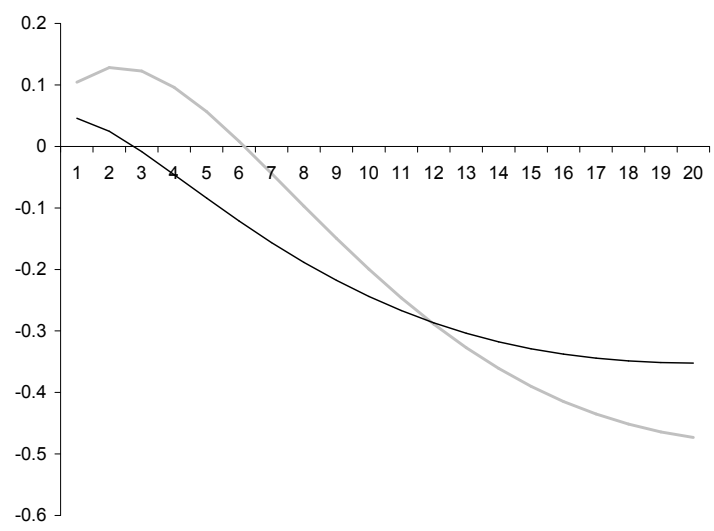

employment

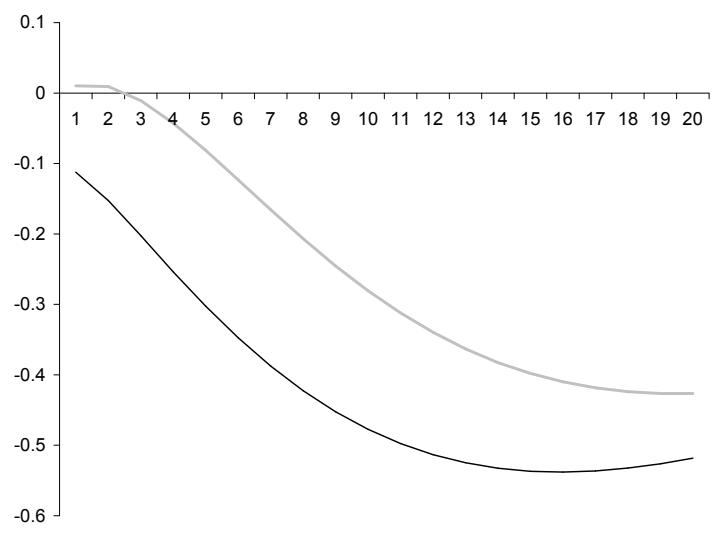

nom. int. rate

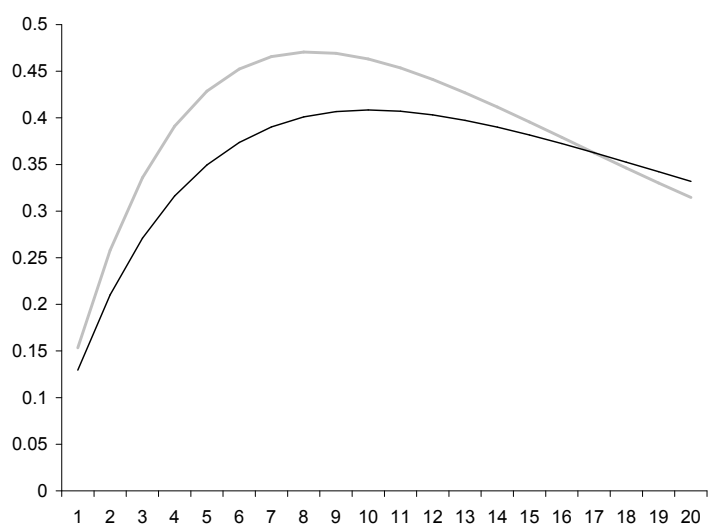

real wage

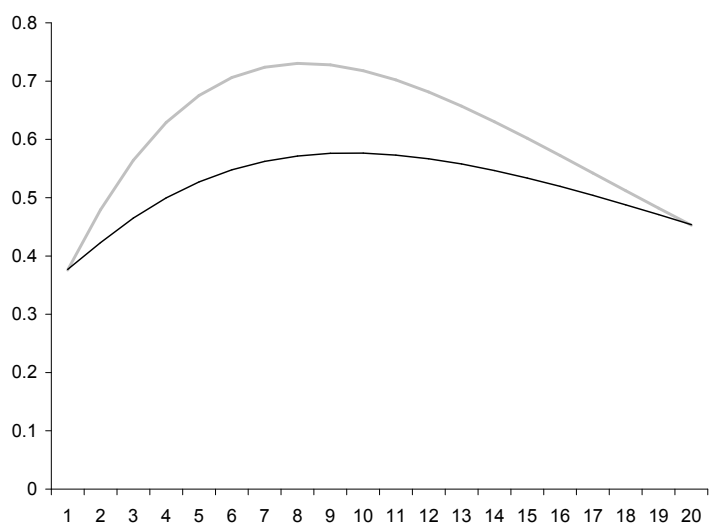

effort

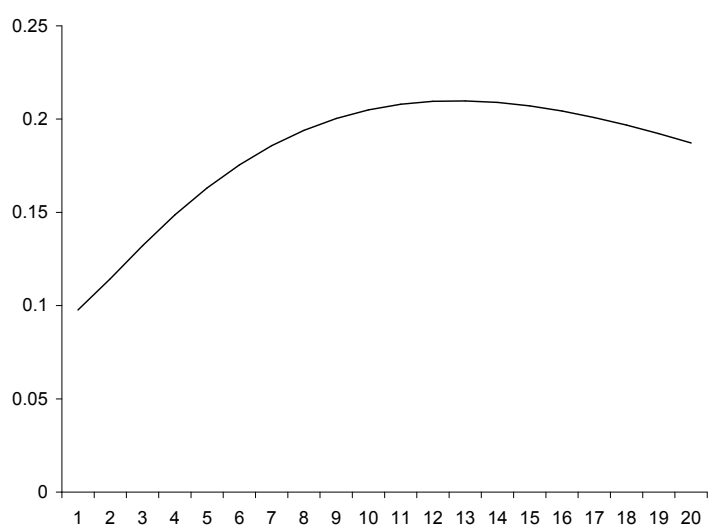

inflation

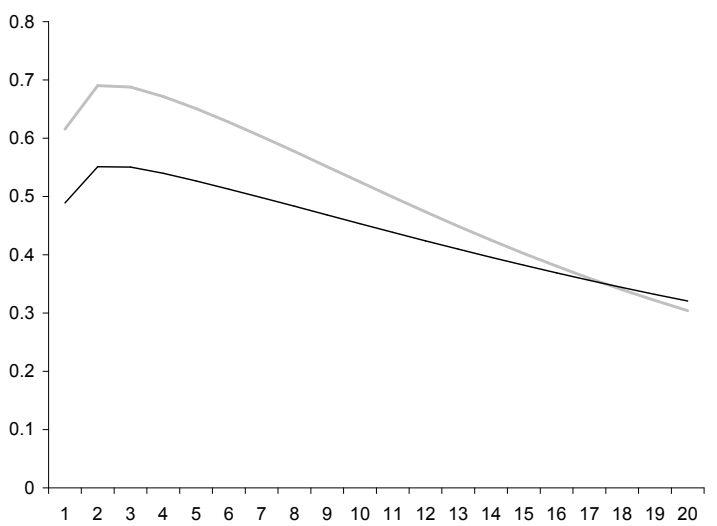

Note: Grey line: benchmark model. Black line: Fair wage model. 
Figure 6: IRF for a productivity shock with monetary policy targeting the natural versus the efficient output gap

GDP

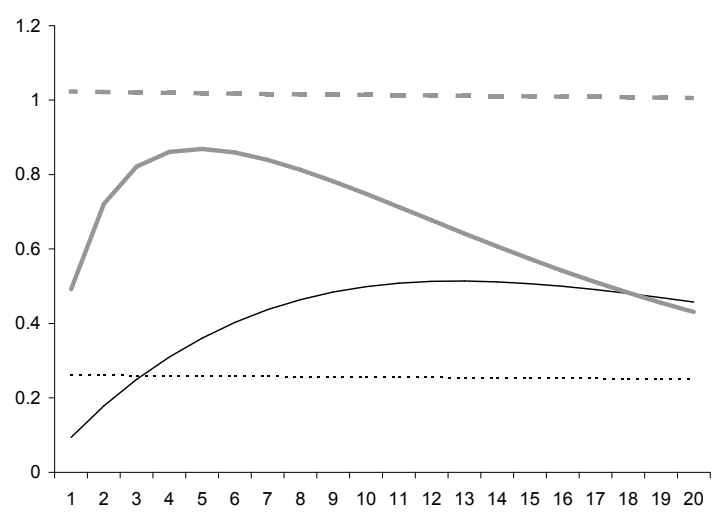

nom.interest rate

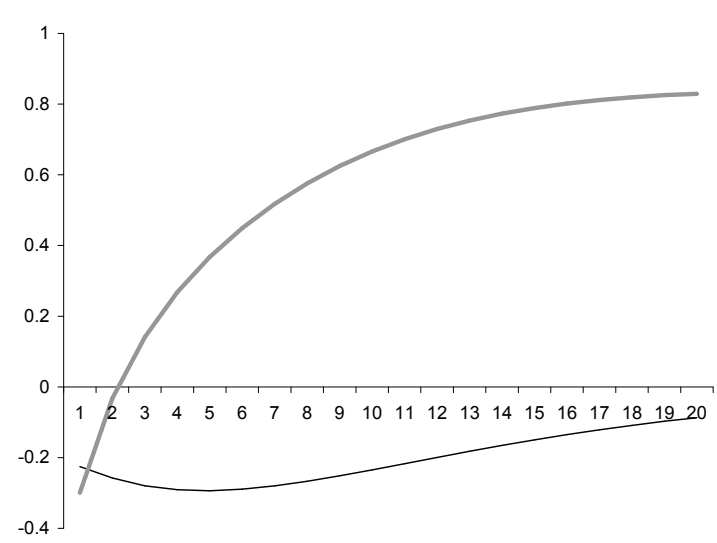

Employment
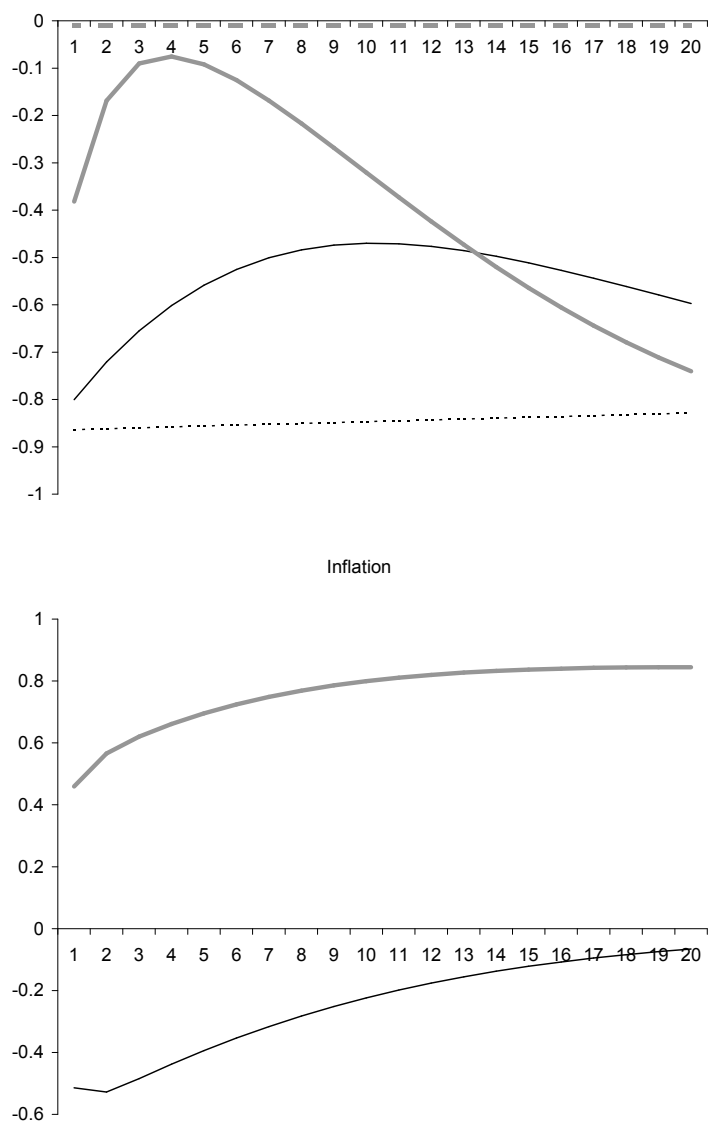

Note: Black line: outcome under natural output gap targeting (dotted lines represent target natural output and employment).

Grey line: outcome under efficient output gap targeting (dotted lines represent target efficient output and employment). 


\section{European Central Bank Working Paper Series}

For a complete list of Working Papers published by the ECB, please visit the ECB's website (http://www.ecb.int)

745 "Market discipline, financial integration and fiscal rules: what drives spreads in the euro area government bond market?" by S. Manganelli and G.Wolswijk,April 2007.

746 "U.S. evolving macroeconomic dynamics: a structural investigation" by L. Benati and H. Mumtaz,April 2007.

747 "Tax reform and labour-market performance in the euro area: a simulation-based analysis using the New Area-Wide Model" by G. Coenen, P. McAdam and R. Straub, April 2007.

748 "Financial dollarization: the role of banks and interest rates" by H. S. Basso, O. Calvo-Gonzalez and M. Jurgilas, May 2007.

749 "Excess money growth and inflation dynamics" by B. Roffia and A. Zaghini, May 2007.

750 "Long run macroeconomic relations in the global economy" by S. Dees, S. Holly, M. H. Pesaran and L.V. Smith, May 2007.

751 "A look into the factor model black box: publication lags and the role of hard and soft data in forecasting GDP” by M. Bańbura and G. Rünstler, May 2007.

752 "Econometric analyses with backdated data: unified Germany and the euro area" by E.Angelini and M. Marcellino, May 2007.

753 “Trade credit defaults and liquidity provision by firms" by F. Boissay and R. Gropp, May 2007.

754 "Euro area inflation persistence in an estimated nonlinear DSGE model" by G.Amisano and O.Tristani, May 2007.

755 "Durable goods and their effect on household saving ratios in the euro area" by J.Jalava and I. K. Kavonius, May 2007.

756 "Maintaining low inflation: money, interest rates, and policy stance" by S. Reynard, May 2007.

757 "The cyclicality of consumption, wages and employment of the public sector in the euro area" by A. Lamo, J.J. Pérez and L. Schuknecht, May 2007.

758 "Red tape and delayed entry" by A. Ciccone and E. Papaioannou, June 2007.

759 "Linear-quadratic approximation, external habit and targeting rules" by P. Levine, J. Pearlman and R. Pierse, June 2007.

760 "Modelling intra- and extra-area trade substitution and exchange rate pass-through in the euro area" by A. Dieppe and T.Warmedinger, June 2007.

761 "External imbalances and the US current account: how supply-side changes affect an exchange rate adjustment" by P. Engler, M. Fidora and C. Thimann, June 2007.

762 "Patterns of current account adjustment: insights from past experience" by B. Algieri and T. Bracke, June 2007.

763 "Short- and long-run tax elasticities: the case of the Netherlands" by G.Wolswijk, June 2007. 
764 "Robust monetary policy with imperfect knowledge" by A. Orphanides and J. C. Williams, June 2007.

765 "Sequential optimization, front-loaded information, and U.S. consumption" by A.Willman, June 2007.

766 "How and when do markets tip? Lessons from the Battle of the Bund" by E. Cantillon and P.-L.Yin, June 2007.

767 "Explaining monetary policy in press conferences" by M. Ehrmann and M. Fratzscher, June 2007.

768 "A new approach to measuring competition in the loan markets of the euro area" by M. van Leuvensteijn, J.A. Bikker,A. van Rixtel and C. Kok Sørensen, June 2007.

769 “The 'Great Moderation' in the United Kingdom” by L. Benati, June 2007.

770 "Welfare implications of Calvo vs. Rotemberg pricing assumptions" by G. Lombardo and D.Vestin, June 2007.

77I "Policy rate decisions and unbiased parameter estimation in typical monetary policy rules" by J. Podpiera, June 2007.

772 "Can adjustment costs explain the variability and counter-cyclicality of the labour share at the firm and aggregate level?" by P. Vermeulen, June 2007.

773 "Exchange rate volatility and growth in small open economies at the EMU periphery" by G. Schnabl, July 2007.

774 "Shocks, structures or monetary policies? The euro area and US after 200I" by L. Christiano, R. Motto and M. Rostagno, July 2007.

775 "The dynamic behaviour of budget components and output" by A. Afonso and P. Claeys, July 2007.

776 "Insights gained from conversations with labor market decision makers" by T. F. Bewley, July 2007.

777 "Downward nominal wage rigidity in the OECD" by S. Holden and F.Wulfsberg, July 2007.

778 “Employment protection legislation and wages" by M. Leonardi and G. Pica, July 2007.

779 "On-the-job search and the cyclical dynamics of the labor market" by M. U. Krause and T.A. Lubik, July 2007.

780 "Dynamics and monetary policy in a fair wage model of the business cycle" by D. de la Croix, G. de Walque and R.Wouters, July 2007. 


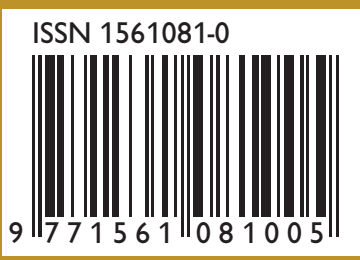

